San Jose State University

SJSU ScholarWorks

Master's Theses

Master's Theses and Graduate Research

Fall 2018

\title{
A Modular Multi-level Converter for Energy Management of Hybrid Energy-Storage Systems in Electric Vehicles
}

Sharon Sanjeev George

San Jose State University

Follow this and additional works at: https://scholarworks.sjsu.edu/etd_theses

\section{Recommended Citation}

George, Sharon Sanjeev, "A Modular Multi-level Converter for Energy Management of Hybrid EnergyStorage Systems in Electric Vehicles" (2018). Master's Theses. 4967.

DOI: https://doi.org/10.31979/etd.94h5-2h6q

https://scholarworks.sjsu.edu/etd_theses/4967

This Thesis is brought to you for free and open access by the Master's Theses and Graduate Research at SJSU ScholarWorks. It has been accepted for inclusion in Master's Theses by an authorized administrator of SJSU ScholarWorks. For more information, please contact scholarworks@sjsu.edu. 


\title{
A MODULAR MULTI-LEVEL CONVERTER FOR ENERGY MANAGEMENT OF HYBRID ENERGY-STORAGE SYSTEMS IN ELECTRIC VEHICLES
}

\author{
A Thesis \\ Presented to \\ The Faculty of the Department of Electrical Engineering \\ San José State University \\ In Partial Fulfillment \\ of the Requirements for the Degree \\ Master of Science
}

by

Sharon Sanjeev George

December 2018 
(C) 2018

Sharon Sanjeev George

ALL RIGHTS RESERVED 
The Designated Thesis Committee Approves the Thesis Titled

\title{
A MODULAR MULTI-LEVEL CONVERTER FOR ENERGY MANAGEMENT OF HYBRID ENERGY-STORAGE SYSTEMS IN ELECTRIC VEHICLES
}

\author{
by \\ Sharon Sanjeev George \\ APPROVED FOR THE DEPARTMENT OF ELECTRICAL ENGINEERING
}

SAN JOSÉ STATE UNIVERSITY

December 2018

Mohamed O. Badawy, Ph.D. Department of Electrical Engineering

David W. Parent, Ph.D. Department of Electrical Engineering

Saeid Bashash, Ph.D. Department of Mechanical Engineering 


\title{
ABSTRACT \\ A MODULAR MULTI-LEVEL CONVERTER FOR ENERGY MANAGEMENT OF HYBRID ENERGY-STORAGE SYSTEMS IN ELECTRIC VEHICLES
}

\author{
by Sharon Sanjeev George
}

Electric vehicles (EVs) are substantial applications of clean energy. Their effectiveness for mainstream transportation is predicated on the efficient use of stored energy within the vehicles' power pack. Among rechargeable storage solutions, lithium-ion (Li-ion) battery cells have high energy density making them suitable to supply the EVs' average power. However, the peak power requirements of the vehicles exert stress on the Li-ion cells due to their low pulsating power capabilities. Ultracapacitors can be used instead as the power-pulsating storage elements given their superior power density. Incorporating the two cell types for energy storage signifies a hybrid configuration that leads to challenging tasks in managing the energy between cells due to varying cell dynamics. Therefore, this study investigated the design of an end-to-end hybrid energy-storage and management system. The limitations of existing power electronics and control schemes were identified based on comparative analysis, both on a cell level and on a system level. Subsequently, an energy system was developed that utilized modular multi-level converters to manage the energy between the different cell types. The formulated control strategy accounted for various power modes and added immense flexibility in charge sharing through diverse switching states. Furthermore, the proposed configuration eliminated the conventional need for a system level drive inverter feeding the EV motor. Electro-mechanical modeling results and physical design merits verified the proposed configuration's effectiveness in improving EV efficiency. 


\section{DEDICATION}

To Dr. Mohamed Badawy, for accepting mentorship for this research project. His profound knowledge in electrical concepts served as a lodestar that enabled me to drive this project to fruition. More than advising on the technical aspects of the project, he showed me how to prioritize engineering tasks efficiently to maintain a continuous process flow - a skill that I continue to rely on in my career as an engineer!

To Dr. David Parent, Dr. Saeid Bashash, and Dr. David Bruck, for their valuable feedback that helped me advance this thesis to its present state!

To Center of Power Electronic Converters and San Jose State University, for providing me with the platform and resources to explore my interests!

To Sanjeev, Nisha, Sajay, Sandra, et. al, for enabling me to pursue my goals, unconditionally!

To the men and women of science, whose ideas and achievements continue to inspire me! 


\section{TABLE OF CONTENTS}

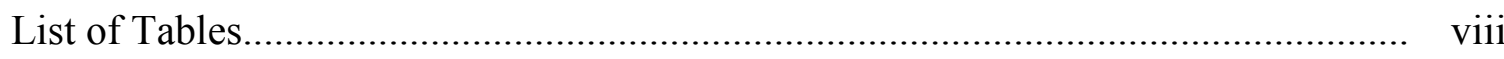

List of Figures......................................................................................... ix

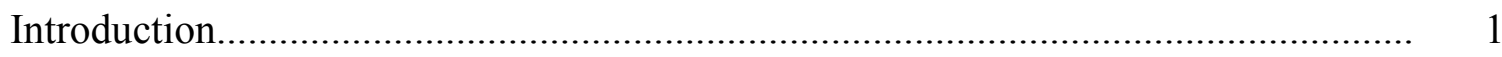

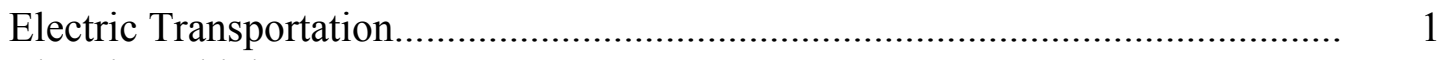

Electric Vehicle Battery ............................................................................... 2

Battery chemistry ......................................................................................... 2

Battery characteristics................................................................................ 4

Electric Vehicle Battery Management System....................................................... 7

Battery management challenges................................................................... 7

Battery management system definition........................................................... $\quad 7$

Battery management system functions............................................................. 8

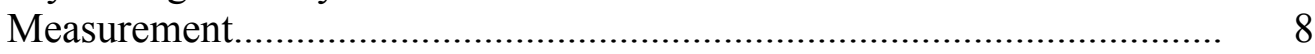

Protection......................................................................................... 8

Cell balancing.................................................................................. 9

Parameter estimation........................................................................... 9

Hybrid Energy-Storage Systems...................................................................... $\quad 10$

Power density in electric vehicles................................................................... 10

Hybrid energy storage challenges................................................................. 11

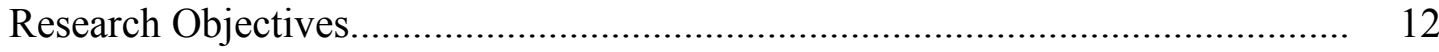

Thesis Outline........................................................................................ 13

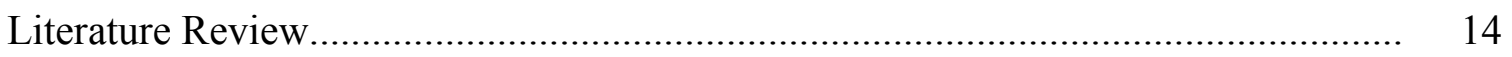

Review of Hybrid Energy-Storage Topologies.................................................... 14

Singular converter configuration........................................................... 14

Cascaded converter configuration.................................................................. 16

Discrete converter configuration.................................................................. 16

Shared converter configuration.................................................................... 17

Review of Energy Management Techniques....................................................... 18

Passive management................................................................................... 19

Active management................................................................................ 20

Capacitor-based converters................................................................. 20

Inductor-based converters................................................................ 21

Modular multi-level converters............................................................. 23

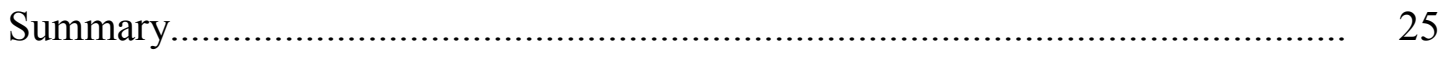

Novel Energy Management System.................................................................. 26

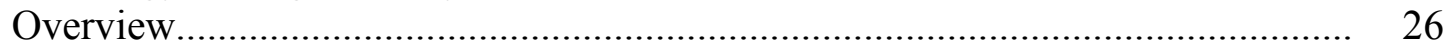

Energy Management System Architecture............................................................ 26

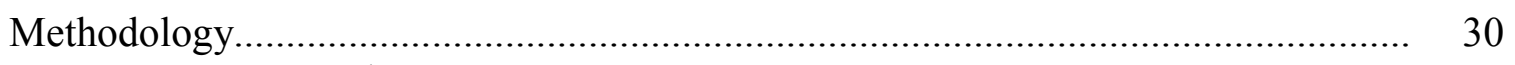

Converter Control Strategy............................................................................ $\quad 30$ 
Switching states............................................................................ $\quad 30$

Pulse width modulation scheme................................................................... 33

State-of-charge estimation and balancing............................................... 34

Energy Management System Hardware.......................................................... 36

Hardware features............................................................................. 36

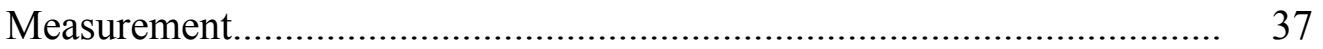

Protection.............................................................................. 39

Digital control.......................................................................... 40

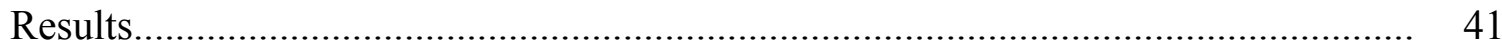

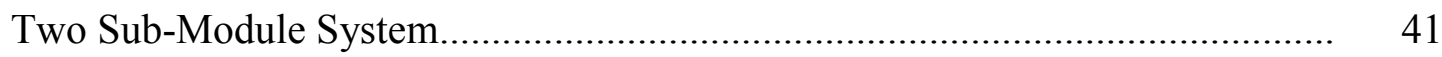

Battery only (low/average power)........................................................ 41

Ultracapacitor only (high power)........................................................ 41

Battery and ultracapacitor (MTPA extension)........................................... 43

Three-Phase System.............................................................................. 43

Energy Balancing of Six Sub-Modules....................................................... 44

Conclusion and Future Work................................................................................ 46

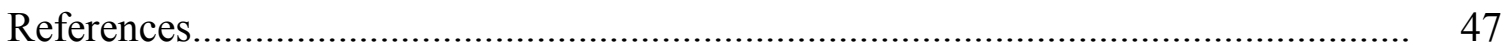




\section{LIST OF TABLES}

Table 1. Sub-Module Converters Switching States........................................... 31 


\section{LIST OF FIGURES}

Figure 1. Cell temperature versus cell voltage (Li-ion) ...................................... 5

Figure 2. Open-circuit voltage versus state-of-charge (Li-ion) ............................... 6

Figure 3. Single converter configuration: (a) battery-converter-ultracapacitor,

(b) ultracapacitor-converter-battery.............................................. 15

Figure 4. Cascaded converter configuration................................................. 16

Figure 5. Discrete converter configuration..................................................... 17

Figure 6. Shared converter configuration.................................................... 18

Figure 7. Shunt resistor balancing circuit........................................................ 19

Figure 8. Switched-capacitor balancing circuit........................................... 20

Figure 9. (a) Single inductor charge balancer, (b) shared transformer charge

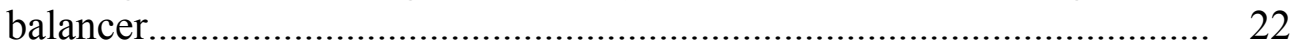

Figure 10. Three-phase modular multi-level converter configuration...................... 24

Figure 11. Novel hybrid energy-storage system for electric vehicles..................... 27

Figure 12. Conduction modes: (a) battery only, (b) ultracapacitor only,

(c) battery +ultracapacitor.

Figure 13. Conventional and novel converters for series-connected energy cells..... 32

Figure 14. Pulse width modulation signals with output waveform........................... 34

Figure 15. Cell state-of-charge estimation and balancing algorithm....................... 35

Figure 16. Sub-module board schematic.......................................................... 37

Figure 17. Gate driver circuit schematic....................................................... 37

Figure 18. Voltage sensor circuit schematic...................................................... 38

Figure 19. Current sensor circuit schematic..................................................... 39

Figure 20. Five-level voltage waveform (battery only)...................................... 42

Figure 21. Five-level voltage waveform (ultracapacitor only).............................. 42

Figure 22. Five-level voltage waveform (battery + ultracapacitor)........................ 43

Figure 23. Three-phase voltage waveform.................................................... 44

Figure 24. State-of-charge balancing of six sub-modules.................................. 45 


\section{LIST OF ABBREVIATIONS}

$\mathrm{AC}$ - Alternating current

ADC - Analog-to-digital converter

BMS - Battery management system

DC - Direct current

EMS - Energy management system

EV - Electric vehicle

HESS - Hybrid energy-storage system

Li-ion - Lithium-ion

MMC - Modular multi-level converter

MTPA - Maximum torque per ampere

OCV - Open-circuit voltage

PCB — Printed circuit board

PDPWM - Phase disposition pulse width modulation

PWM - Pulse width modulation

SEI - Solid electrolyte interface

SOA - Safe operating area

SOC - State-of-charge

$\mathrm{UC}$ - Ultracapacitor 


\section{Introduction}

\section{Electric Transportation}

Transportation plays a vital role in the advancement of human society. In fact, nations rely on various modes of transportation to stimulate social and economic development. However, the surging use of conventional transportation solutions, like automobiles, causes serious problems for the environment. This is mainly because automobiles employ hydrocarbon fuels for vehicle propulsion that produce toxic emissions as by-products. The transportation sector alone is responsible for $24.1 \%$ of the global $\mathrm{CO}_{2}$ emissions (Kassens, 2009). Addition of such greenhouse gases to the natural carbon cycle of the environment produces air pollution and global warming and rapidly depletes the Earth's

finite fuel resources. Hence, sustainable forms of transportation are vital. The need for safe and efficient transportation solutions that rely on clean energy has prompted research and development globally. Therefore, electrification of vehicle powertrains is a breakthrough that helps advance sustainability.

A typical gasoline vehicle contains an internal combustion engine and a fuel tank with an energy conversion efficiency of less than 21\% (Williamson, Lukic, \& Emadi, 2006). On the other hand, pure electric vehicles (EVs) consist of an electric motor for propulsion and a battery pack for energy storage. Electric motors convert electrical energy from the battery to mechanical energy to develop instant torque required for wheel rotation. When the load-side electromotive force exceeds the source voltage, electric motors assume the role of generators and convert mechanical energy to electrical energy. In this way, EVs recover the kinetic energy while braking and use the resulting 
current to recharge the battery. This characteristic property of electric motor drives is featured as 'regenerative braking' and contributes to energy efficiency in EVs. Electric motor efficiency is estimated to be between $76.4 \%$ and $80.2 \%$ when accounting for inverter and parasitic losses (Miller, Holmes, Conlon, \& Savagian, 2011). Battery charging and discharging efficiency of over $90 \%$ can be achieved (Gautam, Musavi, Edington, Eberle, \& Dunford, 2012). Such component efficiency values manifest in EVs resulting in an overall energy conversion efficiency between 59\% and 62\% (All-Electric Vehicles, 2018). Improvements in conversion efficiency can be made using energy-dense and power-dense energy-storage configurations combined with intelligent control of the associated power electronics to reduce losses. Moreover, employing maximum torque per ampere (MTPA) control techniques allow instant torque production with minimum power consumption (Bariša, Sumina, \& Kutija, 2015). Therefore, through judicious use of energy, the EV driving experience can be vastly enhanced, which will in turn facilitate mainstream adoption of the EV paradigm.

\section{Electric Vehicle Battery}

Battery chemistry. Batteries have played a prominent and consistent role in the ever-changing energy trends of the modern age. Their prominence is evident throughout the diverse energy applications that range from low power consumer electronics to high power systems like uninterrupted power supply and EVs. In recent times, lithium-ion (Li-ion) batteries have become the primary choice for energy storage due to their favorable features such as high energy density, low self-discharge rate, and long lifetime (Lu, Han, Hua, \& Ouyang, 2013). These attributes have enabled the adoption of Li-ion 
chemistry battery cells for traction packs in modern EVs. Popular cell chemistries include $\mathrm{LiFePO}_{4}$ (lithium iron phosphate), $\mathrm{LiMnO}_{2}$ (lithium manganese oxide), $\mathrm{LiMnNiCo}$ (lithium manganese nickel cobalt), $\mathrm{LiCoO}_{2}$ (lithium cobalt oxide), $\mathrm{Li}_{4} \mathrm{Ti}_{5} \mathrm{O}_{12}$ (lithium titanate), and $\mathrm{LiNiO}_{2}$ (lithium nickel oxide).

The constituents of a typical Li-ion cell are discussed below.

- Cathode: the positive electrode whose active materials are made of $\mathrm{Li}$-ion composites. ${ }^{1}$

- Anode: the negative electrode whose active materials are carbon-based, e.g., graphite.

- Electrolyte: a liquid or semi-solid medium that enables the flow of ions between the electrodes.

- Separator: a porous layer that prevents electrical contact between cathode and anode while allowing the exchange of $\mathrm{Li}^{+}$.

Through a reversible process called intercalation, lithium ions move back and forth between the active materials of the cathode and the anode, resulting in charge transfer.

A promising trend in terms of safety and higher energy density is the development of solid-state batteries which consist of a solid electrolyte. Such batteries are tolerant to high temperatures and mitigate the safety risks posed by cells using liquid electrolytes (Agrawal \& Pandey, 2008). Similarly, active research is underway ranging from modifying the type of materials to modifying the structure of the battery cell to accommodate higher energy density and specific energy without compromising on safety and life cycle (Etacheri, Marom, Elazari, Salitra, \& Aurbach, 2011). Li-ion cells exist in

\footnotetext{
${ }^{1}$ A cell's chemistry is usually named after its cathodic material.
} 
various formats like pouch cells, cylindrical cells, and prismatic cells. Cell format is chosen based on energy requirements, physical dimension and scale of the application (BU-301a: Types of Battery Cells, 2017).

Battery characteristics. Battery characterization is a process used to determine whether a type of battery is suitable for an application. Some of the most important characterization parameters are temperature, current, and voltage. While current provides instantaneous cell operation conditions, temperature and voltage are determinants of long-term cell operation constraints. Li-ion cell operating temperatures typically range from $-20^{\circ} \mathrm{C}$ to $60^{\circ} \mathrm{C}$; however, high power applications may require an operating range of $-40^{\circ} \mathrm{C}$ to $85^{\circ} \mathrm{C}$ (Andrea, 2010). Similarly, Li-ion cell open-circuit voltage (OCV) variation limits are typically between 4.2 and $2.5 \mathrm{~V}$. Through rigorous testing and failure analysis, cell manufacturers define the safe operating windows of the battery. If a cell's temperature or voltage moves outside of the pre-defined window, the resultant rapid decrease in battery performance is possibly hazardous.

Lu et al. (2013) described the effects of temperature on the chemical constituents of a cell (alternatively depicted in Figure 1). Charging of cells at a temperature much lower than $0^{\circ} \mathrm{C}$ causes lithium plating to occur. This leads to the formation of "dendrites" that pierce through the solid-electrolyte interface (SEI) layer, causing a short within the cell. Therefore, heating may be required to prevent cell damage at low temperatures. At high temperatures $\left(>90^{\circ} \mathrm{C}\right)$, the SEI layer begins to decompose while catalyzing side reactions between the negative electrode and electrolyte, releasing combustible gases. Gases are further released when the temperature increases beyond $130^{\circ} \mathrm{C}$ and the cell separator 
begins to breakdown. This prompts the decomposition of the positive electrode and the release of oxygen gas. Beyond $200^{\circ} \mathrm{C}$, the electrolyte decomposes and is exposed to the oxygen, resulting in a further and sharp elevation in internal cell temperature.

Consequently, the cell constituents become permanently damaged, culminating in thermal runaway that is hazardous, as the cell might explode or catch fire. Therefore, air and fluid cooling sub-systems are used for thermal management in battery EVs. Such sub-systems extend the battery management system (BMS) functionality to ensure that the cell's temperature stays within the safe operating area (SOA), thereby enhancing battery endurance and performance.

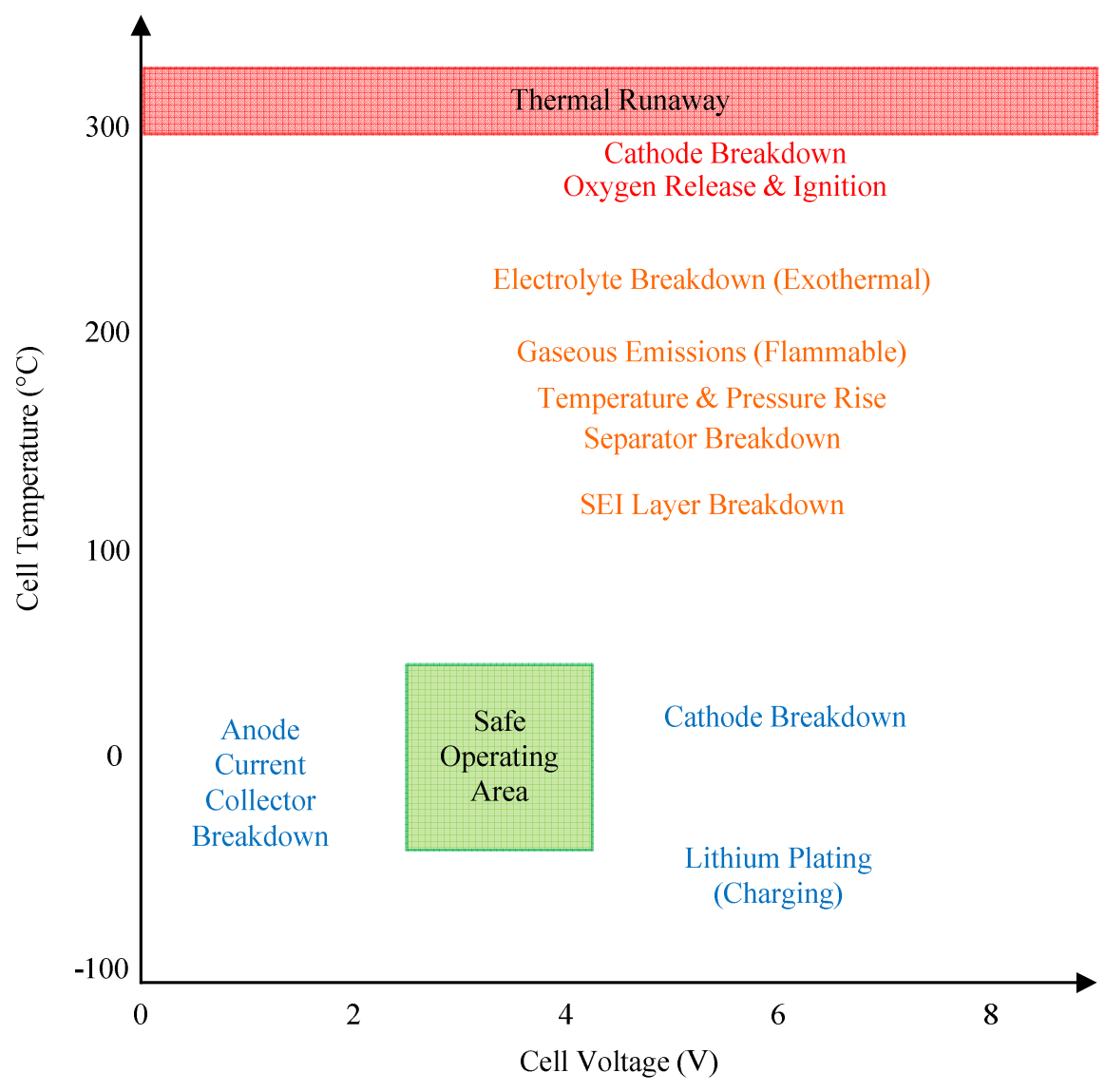

Figure 1. Cell temperature versus cell voltage (Li-ion). 
Another challenge for the use of cells derived from the Li-ion chemistry is the accurate estimation of cell state-of-charge (SOC). In conventional battery chemistries, a one-to-one relationship can be established between the OCV and SOC values. Therefore, simple voltage measurement is adequate for estimating cell SOC. In Li-ion cells, however, the variation in OCV is non-linear which makes it a poor indicator of SOC (Andrea, 2010). The cell voltage drastically changes towards the endpoints of the curve, while a significant portion of the curve takes a plateaued form in the middle (Figure 2). For example, the OCV elevates in the order of $300 \mathrm{mV}$ towards the charged end and plummets at the rate of $500 \mathrm{mV}$ towards the discharged end, subsuming most of the cell's operating range in the flat portion. Therefore, OCV cannot be considered an accurate representation of the Li-ion battery SOC. This motivates the use of high precision sensing or intelligent parameter estimation by the BMS.

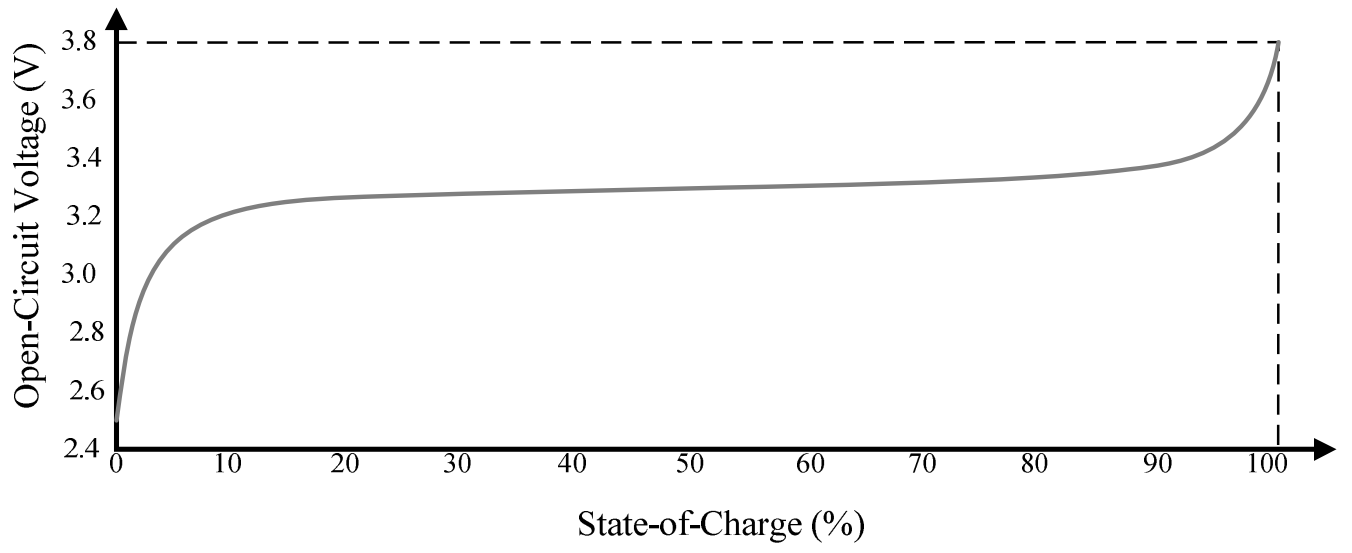

Figure 2. Open-circuit voltage versus state-of-charge (Li-ion). 


\section{Electric Vehicle Battery Management System}

Battery management challenges. In high voltage applications, Li-ion battery packs are composed of many cells connected in series which entail higher risks in terms of safety. Depending on the cell chemistry, there are thermal and voltage constraints that need to be accounted for during the design of battery modules. Moreover, varying internal impedances and self-discharge rates of the individual cells lead to a drastic imbalance of cell capacities over long periods of use. In such a scenario, overcharging of cells can cause pack failures, while deep discharging can cause heating issues that deteriorate the battery life span (Lu et al., 2013). A large EV battery is a substantial investment, that if not managed properly, can incur additional maintenance costs. Thus, a BMS is necessary to extract maximum power while maintaining the battery charging and discharging rates within the desirable operating limits. A well designed BMS improves the battery life span, ergo, improving the range and the performance of the vehicle.

Battery management system definition. A system designed to ensure the safe and reliable operation of battery cells is called a battery management system. Based on the application, a typical BMS achieves a set of primary objectives:

1. Monitor and report the cell status.

2. Protect the battery and the host system.

3. Estimate cell parameters and states.

4. Maximize system life and performance. 
Battery management system functions. In EVs, a BMS is an embedded system interconnected with the vehicle control unit and the battery pack and primarily performs measurement, protection, cell balancing, and parameter estimation.

Measurement. Voltage, current, and temperature measurements form the basis of all control by the BMS. Measurements are performed on a cell level and/or pack level with varying rates and accuracies depending on cell chemistry. Sophisticated BMSs measure the parameters of all the cells and use the data to establish charging strategies. The measurements also enable the BMS to perform high order functions such as SOC estimation and cell balancing. A typical BMS circuit consists of voltage-sensing integrated circuit (IC) chips, where a single chip can measure multiple cell voltages. Current measurement usually involves resistor-based shunt sensors or hall-effect sensors. External cell temperatures can be sensed with thermocouples or thermistors. These sensing devices are coupled with analog-to-digital converters (ADC) that convert and store the necessary data to be used by the BMS.

Protection. An essential part of building a fault-tolerant BMS is to ensure that there are mechanisms in place that prevent the battery cells from operating outside their SOA. Based on the voltage and temperature limits, the BMS regulates the charge and discharge rates of the cells. When a cell approaches its upper limit of SOC, the BMS places a request to gradually reduce the charging current. Similarly, when a cell approaches its lower limit of SOC, the BMS reduces the discharging current. In extreme charging or discharging conditions, the BMS may interrupt the pack current altogether and activate thermal management features to bring the cells back to their SOA. Constant current 
constant voltage $(\mathrm{CCCV})$ is a popular charging strategy that applies constant current to rapidly charge cells to approximately $70 \% \mathrm{SOC}$ and then applies constant voltage to allow trickle charging up to $100 \%$, thus preventing overcharging (BU-409: Charging Lithium-ion, 2018). Discharging of cells during loading has a diverse profile based on the application and requires a customized current control strategy that can be determined through battery characterization.

Cell balancing. Cell balancing is the process of equalizing individual cell SOCs using some control topology such that the weaker cells are compensated for by the stronger cells. In a multi-cell Li-ion battery system, the self-discharge rates and the internal impedances of individual battery cells may vary from one another due to manufacturing imperfections. These imperfections become magnified over time and affect cell capacities, causing some cells to become "stronger" than others. Additionally, the stress levels on the weak cells become more severe with each cycle of charge and discharge. As a result, the overall health of the battery pack deteriorates, thereby increasing the chances of a premature failure. To counter this issue, the BMS performs cell balancing by regulating the charge and discharge rates of each cell such that all the cells have similar SOCs at the end of the balancing process. During charging, cells with low SOC are charged more than cells with high SOC. Conversely, during discharging, cells with high SOC are discharged more than those with low SOC.

Parameter estimation. Estimation of energy and power is necessary to optimize the use of the battery in a mobile device. These quantities give an indication of how much longer the device can be used and how it should be used in the immediate future. In EVs, 
knowledge of those parameters allows the implementation of a "fuel-gauge" feature that reports the remaining battery charge. The range of the vehicle is implied by the energy available, while limits on acceleration or regenerative braking are inferred from the available pack power. However, the challenge lies in obtaining the specific numbers on energy and power, since direct measurement of these quantities is impossible. Instead, they need to be estimated using measurable quantities, specifically, the cell voltages, the pack current, and the cell temperatures. Available energy can be estimated based on prior appraisals of battery SOC and capacity. Similarly, prior knowledge of cell SOCs and internal resistances allows the estimation of available power. In some cell chemistries, the voltage is considered an accurate measurement of the cell's SOC, but that may not be true for Li-ion cells where cell voltage is merely an indicator of SOC. This is because cell voltage is affected by external factors such as temperature and resting period. On the other hand, SOC is a representation of the average concentration of lithium ions present in the electrodes. BMSs used in EVs incorporate advanced algorithms to perform estimates either instantaneously or during regular intervals.

\section{Hybrid Energy-Storage Systems}

Power density in electric vehicles. Batteries are generally characterized by their energy density. Energy density is the amount of energy stored per unit mass and is measured in Watt-hour per kilogram $\left(\mathrm{Wh} \mathrm{kg}^{-1}\right)$. Power density is the rate of energy transfer measured in Watt per kilogram $\left(\mathrm{W} \mathrm{kg}^{-1}\right)$, which signifies the instantaneous power transfer capability of an energy storage device. Li-ion battery packs used in EVs have high energy density that is a proportional indicator of the vehicle's driving range. 
However, high energy density does not necessarily mean high power density. The power density of the battery determines the acceleration and regenerative braking limits of the EV. Rapidly changing drive profiles of an EV demand instantaneous power fluctuations from time to time. Li-ion cells have low pulsating power capability, which is an impediment to developing a system efficient in high power processing.

Hybrid energy storage challenges. The sensitive operating characteristics of Li-ion battery cells present various design and control challenges. The usage of a battery as the sole storage device in an EV limits the system power density due to the low pulsating power of Li-ion batteries. Such drawbacks can be compensated for by using alternate energy storage elements such as ultracapacitors in conjunction with battery cells to form a hybrid energy storage system (HESS).

Ultracapacitors (UCs) are high capacity capacitors that are approximately 60 times more power-dense than batteries. They have negligible internal resistance compared to battery cells resulting in superior power processing efficiency. This can be attributed to a fundamental difference in the charge-storing mechanism between the two energy cell types; battery cells use chemical reactions to store charge, while UCs use an electric field to hold charge. As a result, much higher charge transfer rates can be observed in UCs than in batteries. Moreover, the constituents of a battery cell degrade over time shortening cell life span. No such issue occurs in UCs. These characteristics allow UCs to last thousands more cycles of charge and discharge without the temperature effects of battery cells. 
Thus, the power density deficiency of a battery-only system can be alleviated by integrating UCs with battery cells. The stress on battery cells can be reduced by throttling the high C-rate current drawn from them. Instead, the UCs can be used for supplying peak power during traction or for accepting regeneration power during braking. Employing such hybrid systems can vastly improve the power processing efficiency during the rapidly changing driving schedule of an EV (Cao \& Emadi, 2012; Park, Kim, \& Chang, 2013).

\section{Research Objectives}

Based on the comparative analysis of conventional hybrid energy storage and management schemes, the author seeks to develop a novel energy-storage configuration for EV application that incorporates a specific set of features:

Hybrid energy cells - To compensate for the relatively low power density of a fully battery-based system.

High energy and power densities - To improve the efficiency of power processing during the rapidly changing EV driving schedules.

Low power loss - To maximize the real power available to the EV and minimize unnecessary dissipation by the power electronic circuitry.

Modularity - To reduce converter sizing and to allow easy scaling.

Intelligent control - To accommodate the diverse charging/discharging dynamics of the hybrid energy cells. 


\section{Thesis Outline}

In this thesis, the author presents the research on different power electronic configurations and control techniques involved in the design of a hybrid energy storage and management system. The thesis is divided into six parts; The complex issue of energy management and the advantages of HESS in EVs are investigated in the "Introduction." Latest trends in the respective areas are examined in the "Literature Review." A new type of energy management system is proposed in the "Novel Energy Management System" section. Its working mechanism and hardware prototype are described in the "Methodology" section. Simulation results of the novel configuration are collated in "Results." Thesis conclusion and intuitions for future work are discussed in "Conclusion and Future Work." 


\section{Literature Review}

\section{Review of Hybrid Energy-Storage Topologies}

Energy storage in many types of electrochemical cells, namely, lead-acid battery, Li-ion battery, UC, fuel cell, and so forth has been studied (Luo, Wang, Dooner, \& Jonathan, 2015). A storage system that employs only one type of cell has the advantage of reduced control complexity but compromises on either energy density or power density. For superior power transfer efficiency, the storage system must excel in both energy/power density metrics. Thus, a hybrid cell configuration is widely preferred for high efficiency energy storage as combined cell types can compensate for the shortcomings of one another. In this regard, the combination of battery and UC shows promise in mobile devices. Using switching converters for control, the hybrid energy-storage format can be adopted in various forms.

Singular converter configuration. In this configuration, a bi-directional converter is connected to either the battery or the UC bank, while the other is connected directly to the motor drive. In the battery-converter-ultracapacitor configuration (Figure 3a), the battery can be effectively operated over a wide range of voltages as set by the connected converter (Ortúzar, Moreno, \& Dixon, 2007). The UC bank can support pulsating power conditions without the battery. However, the direct current (DC) link undergoes wide fluctuations in voltage, which is detrimental to the UC bank since it is devoid of an interfacing converter. The system's operating range must be limited to make effective power usage from the UC bank. 
Alternatively, the energy bank positions can be interchanged, forming the ultracapacitor-converter-battery configuration shown in Figure 3 b (Gao, Dougal, \& Liu, 2005). In this case, the UC bank can be operated over a wide range of voltages provided that the converter is sized for large power processing. However, the direct connection of the DC link to the battery places constraints on load-side voltage variation. This is because drastic power fluctuations put the battery at the risk of violating its safe operating conditions.

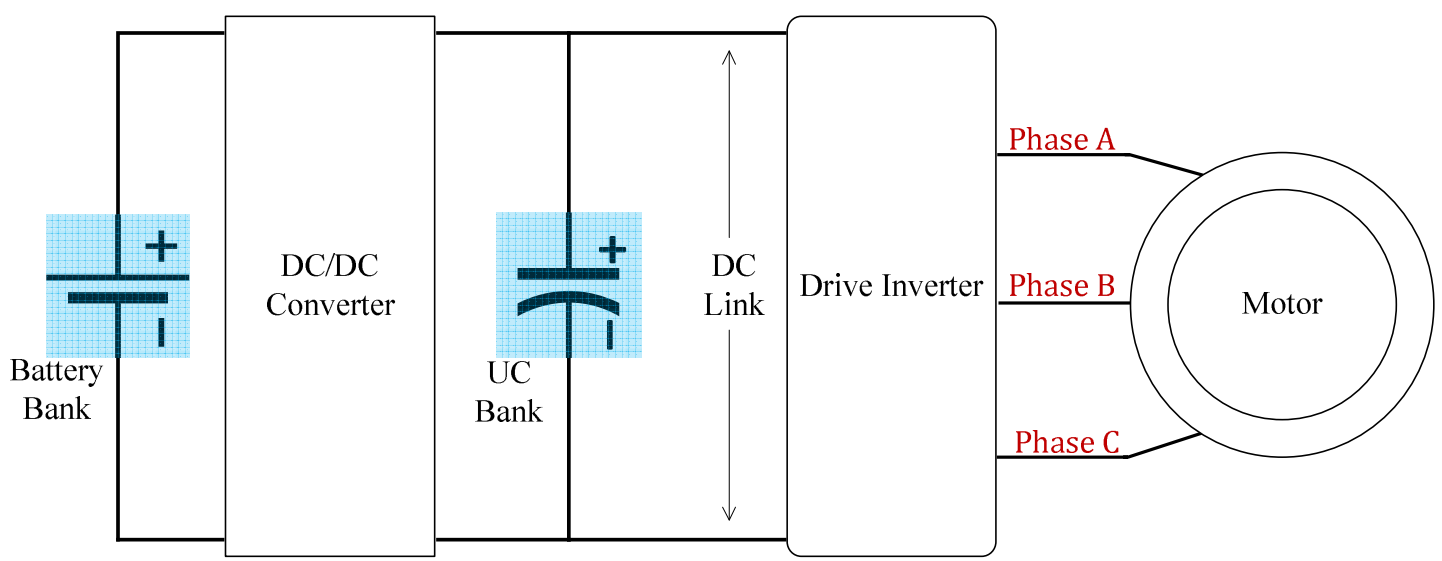

(a)

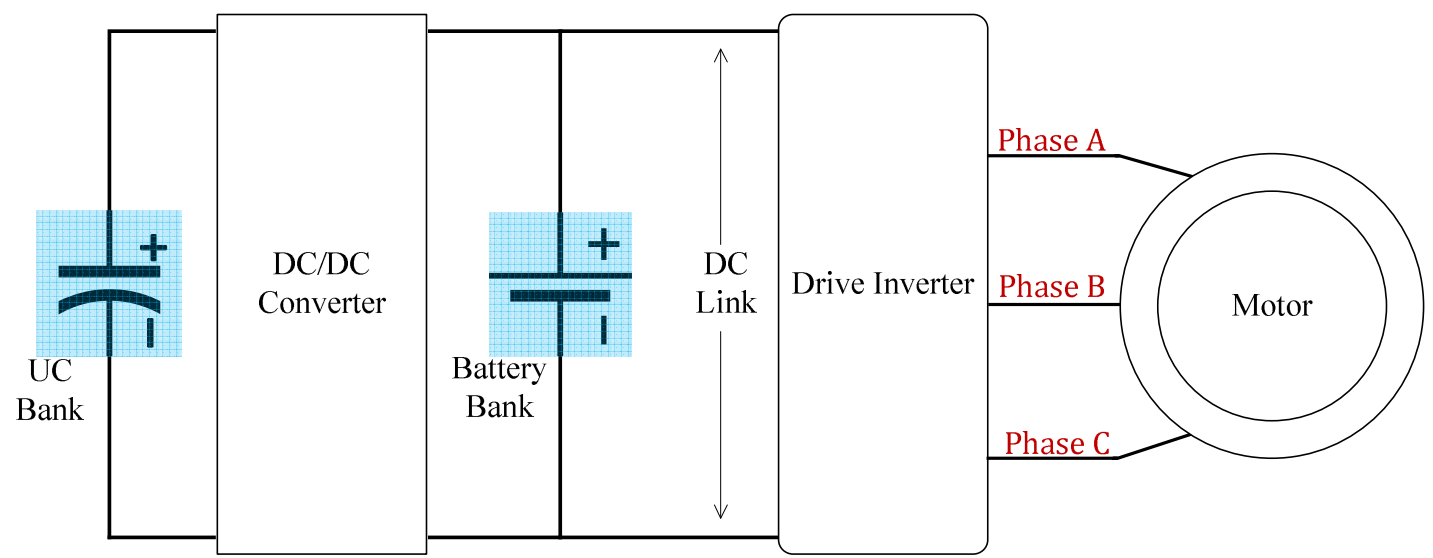

(b)

Figure 3. Single converter configuration: (a) battery-converter-ultracapacitor, (b) ultracapacitor-converter-battery. 
Cascaded converter configuration. A logical power electronic solution, to accommodate the different power dynamics of the battery and UC, is to add more converters (Lukic, Wirasingha, Rodriguez, Cao, \& Emadi, 2006). In the cascaded converter configuration, both the UC bank and the battery have interfacing converters that separate it from the load, as shown in Figure 4.

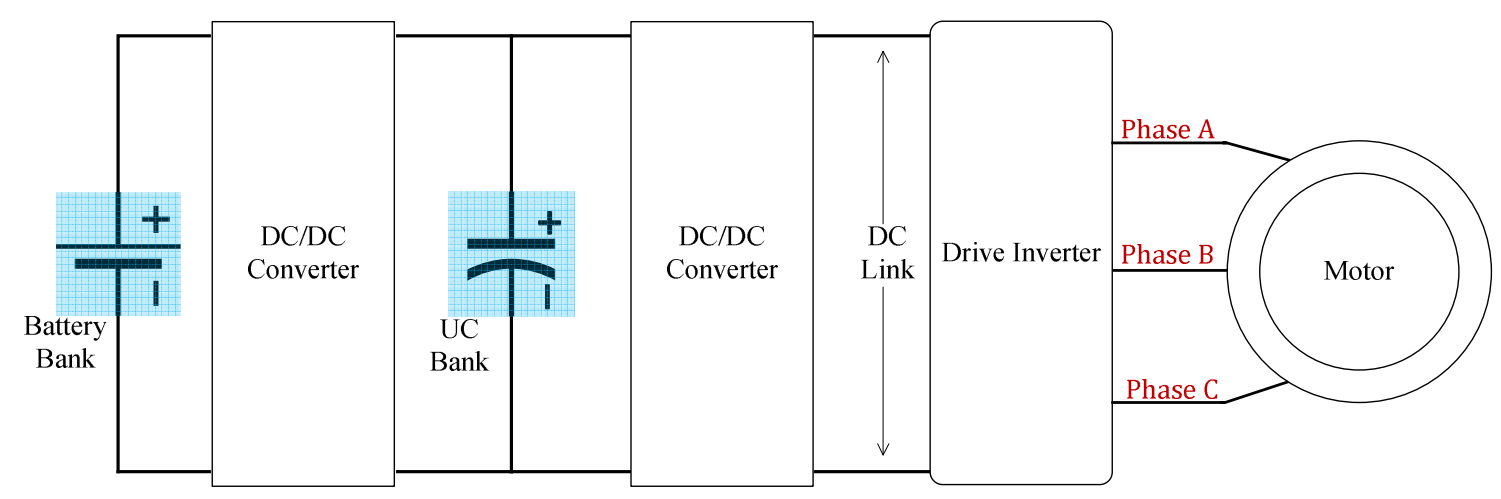

Figure 4. Cascaded converter configuration.

A major advantage of this configuration is that it allows flexible control of the power contributions of both UC and battery banks. Although this configuration overcomes the functional shortcomings of the singular converter configuration, the additional converters incur additional costs. Moreover, they need to be sized to process large power from the individual energy banks.

Discrete converter configuration. Modification of the cascaded converter configuration from series to parallel results in the discrete structure shown in Figure 5. Given two fully sized converters, the outputs can be distinctly connected to the DC link, enabling independent control of the power contributions of the battery and the UC banks (Napoli, Crescimbini, Capponi, \& Solero, 2002). 


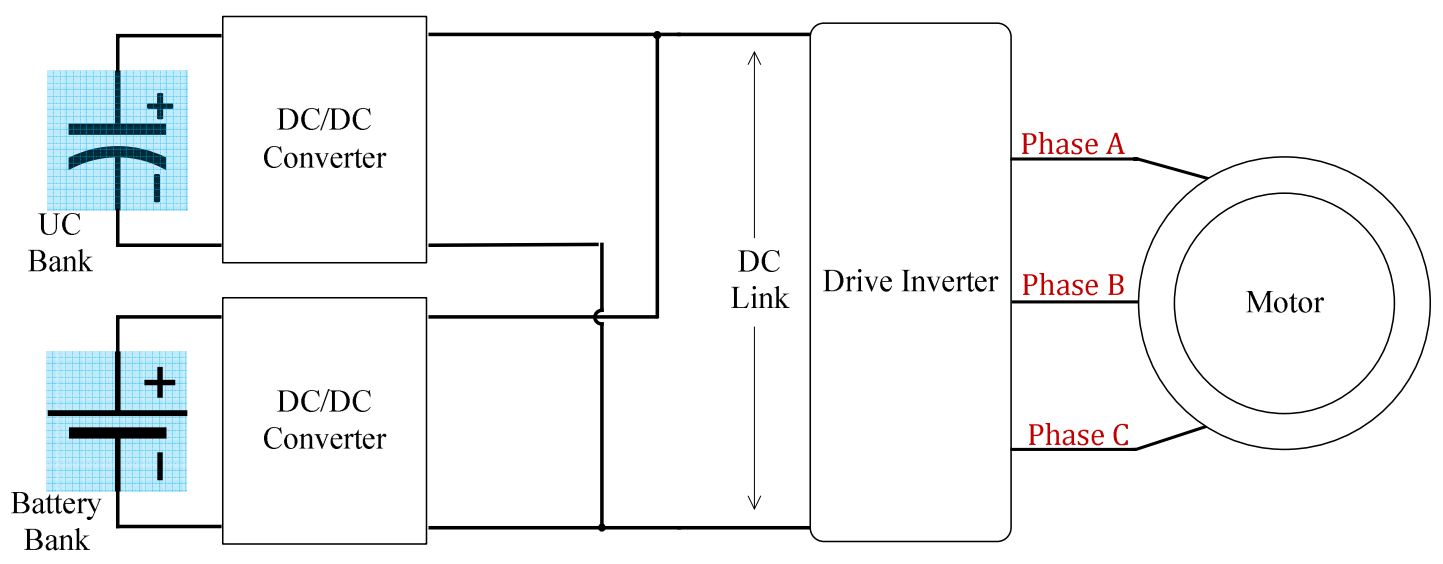

Figure 5. Discrete converter configuration.

In addition, the voltage balancing between the energy banks becomes less constrained due their discrete structure. However, full-scale bi-directional converters are required to make proficient utilization of power from each energy bank which can be expensive.

Shared converter configuration. The need for fully sized converters for the energy banks makes the discrete converter configuration unsuitable for cost sensitive applications. To reduce the overall system cost while integrating hybrid energy sources, the shared converter configuration was proposed (Napoli et al., 2002). A single bi-directional converter combines multiple energy sources through a multi-input topology. The storage banks are connected to the multi-input converter, as shown in Figure 6. However, careful allocation of power with this configuration predicates a complex control structure. 


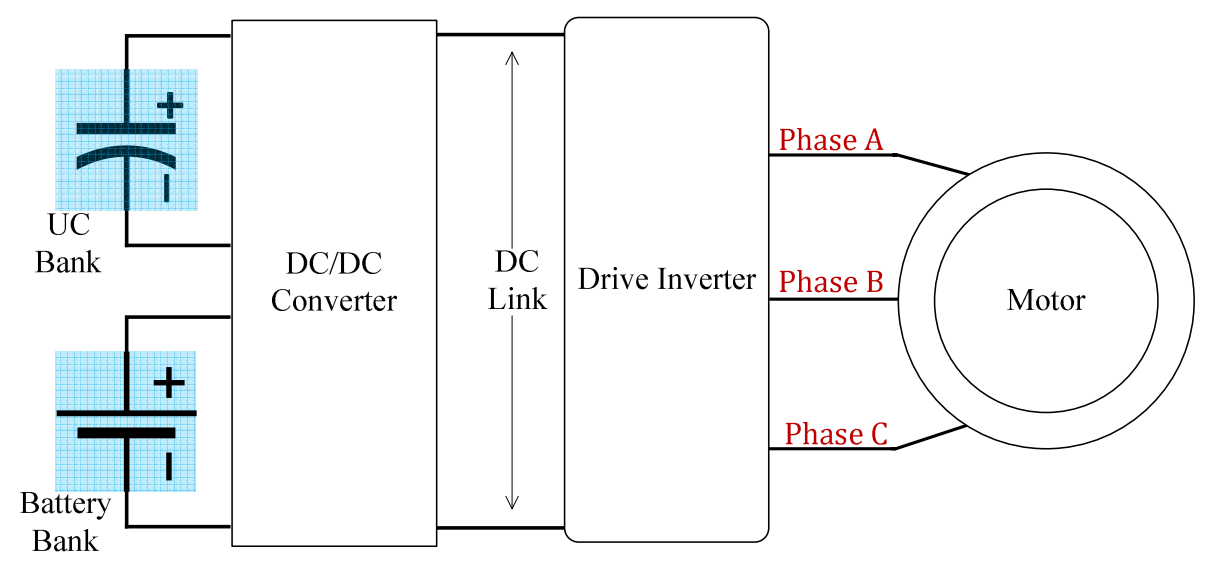

Figure 6. Shared converter configuration.

\section{Review of Energy Management Techniques}

Battery cell capacity is determined by a multitude of factors including cell impedance, temperature, age, and load. Consequently, the capacities of cells present in a battery pack vary from one another even if they are of the same specification (Lu et al., 2013). In high voltage applications, the pack voltage is the sum of individual cell voltages of a series-connected string. With the same current drawn from the series-connected cells, an imbalance in cell SOCs is observed due to varying capacities between neighboring cells. The SOC mismatch widens over long periods of use when some cells are overcharged or excessively discharged than others. This could result in a battery pack failure and interrupt system operation (Lu et al., 2013). Therefore, a cell balancing mechanism is necessary as a function of the device's BMS to maintain the battery charging and discharging rates within the desirable operating limits. Cell balancing is the process of equalizing voltage or SOC of battery cells. Numerous schemes have been put forward on this front and they can be categorized as passive and active management on the basis of their balancing mechanism. 
Passive management. Passive management is based on the principle of energy dissipation. The task of energy balancing is performed using switching circuits consisting of resistive elements. The shunt resistor balancing is a popular passive management technique (Moore \& Schneider, 2001). In this method, parallel shunt resistors are connected to each battery cell of a series string via switches (Figure 7). The resistors are capable of shunting excess charge current when the cells become fully charged (Moore \& Schneider, 2001). The corresponding switches introduce flexibility in control by enabling selective shunting of battery cells. The BMS performs cell balancing by dissipating excess energy through the resistors, or by bypassing a part of the charging current of cells with high SOC until those with low SOC reach the same level. The shunt resistor method is one of the simplest balancing topologies that can be implemented for battery systems with known charging and discharging rates. However, the method is inefficient as significant energy is dissipated as heat via the connected resistors. Use of this method for EV application requires resistors and switches rated for high power. Moreover, the control structure needs to be expanded to include a sophisticated thermal management unit to maintain battery cells within the SOA.

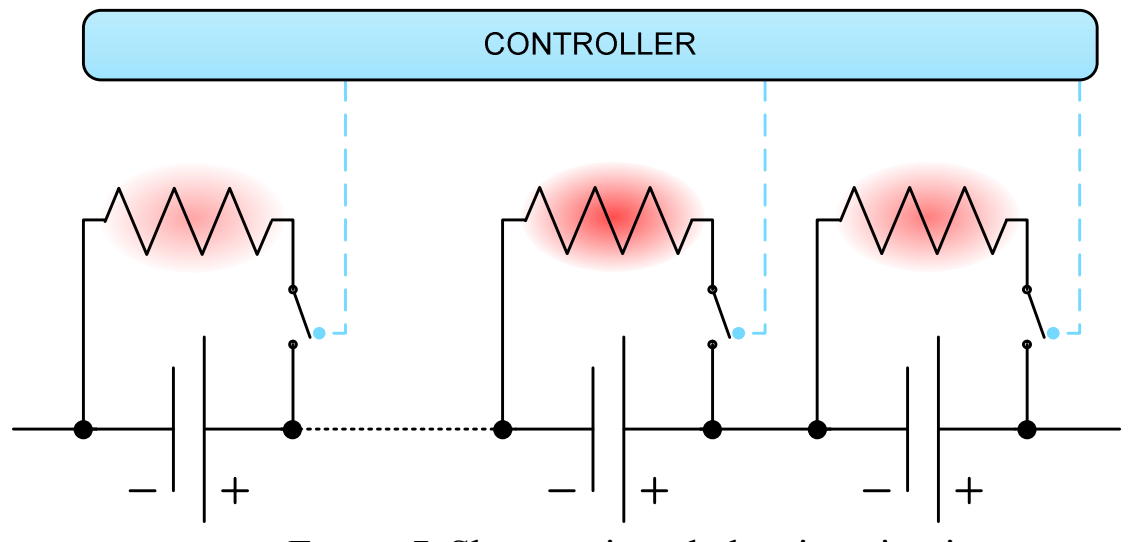

Figure 7. Shunt resistor balancing circuit. 
Active management. Active management is based on the principle of energy sharing rather than energy dissipation. Semiconductor-based switching circuits connected with capacitors, inductors and/or transformers are utilized for implementing non-dissipative charge balancing topologies.

Capacitor-based converters. In many applications where size is a constraint, capacitor-based switching circuits are employed for multi-cell battery management. The fast response of capacitors during switching enables the implementation of time-sensitive control strategies. The switched-capacitor balancer is a popular non-dissipative charge balancing scheme (Figure 8) (Moore \& Schneider, 2001). A pair of complementary signals is triggered in a synchronous pattern to control the switches. The capacitors are switched back and forth repeatedly until they bring the battery cell voltages in the series string to equal values. Simplicity in control makes the implementation and scaling of this balancing topology relatively easy.

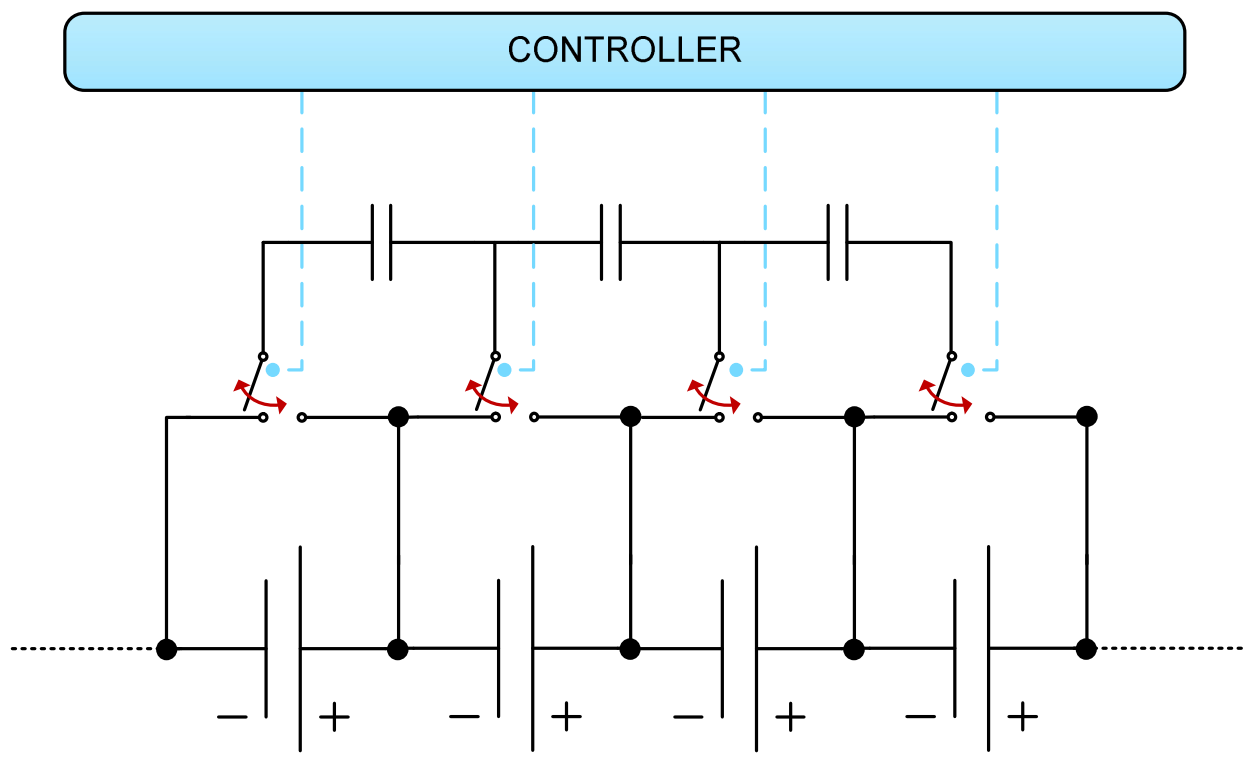

Figure 8. Switched-capacitor balancing circuit. 
However, experiments show that the capacitors and switches undergo significant stress due to large inrush current when a fully discharged capacitor is connected to a battery (Hoque, Hannan, Mohamed, \& Ayob, 2017). Hence, the resonant switched capacitor method was proposed to alleviate capacitor stress by adding small inductors in series with the capacitors (Yuanmao, Cheng, \& Yeung, 2012). In addition to limiting the current ripple, the inductor-capacitor pair in the circuit achieves zero current switching which minimizes switching losses. With these balancing circuits, however, energy is transferred only between adjacent battery cells in one cycle. Energy transfer between cells on either ends of the series string can prolong the total equalization time with a significant portion of the energy lost along the energy transfer path (Moore \& Schneider, 2001; Yuanmao et al., 2012). Moreover, capacitor charge shuttling is based on automatic voltage equalization which is unsuitable for large scale energy management of some Li-ion battery packs. ${ }^{2}$

Inductor-based converters. Inductors or transformers are used as the primary energy-sharing components in this class of energy management converters. The single inductor charge balancer transfers equalization current from a strong cell (high energy) to a weak cell (low energy) (Park S.-H., Kim, Park, Moon, \& Yoon, 2009). Based on sensed voltages, switches connecting the strongest cell and the energy sharing inductor are closed thereby charging the inductor. On selecting the weakest cell, the corresponding switches are turned on establishing a discharge path from the inductor to the weak cell (Figure 9a). The presence of a single magnetic component is advantageous; however,

\footnotetext{
${ }^{2}$ Due to non-linear OCV-SOC relationship of Li-ion battery [Refer section : Introduction].
} 
failure of the component under some circumstance compromises the energy management system. A similar functionality is exhibited by a BMS employing a shared transformer which consists of a primary winding and multiple secondary windings (taps) for each cell, as shown in Figure 9b (Li, Mi, \& Zhang, 2013). Advantages of this topology include fast equalization and minimal core losses.

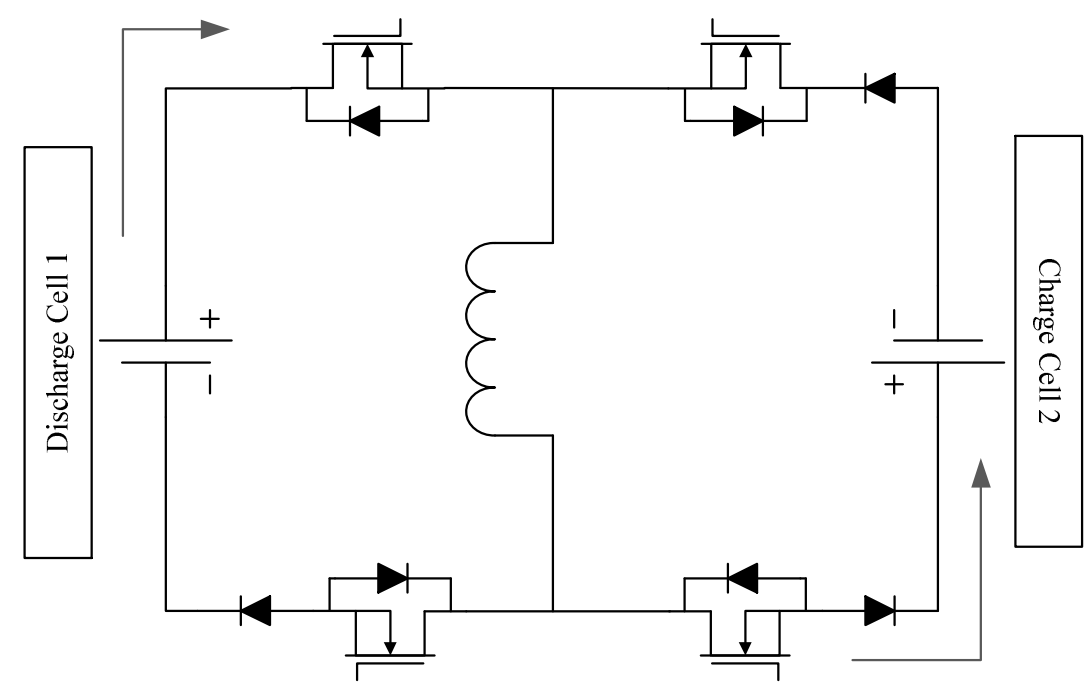

(a)

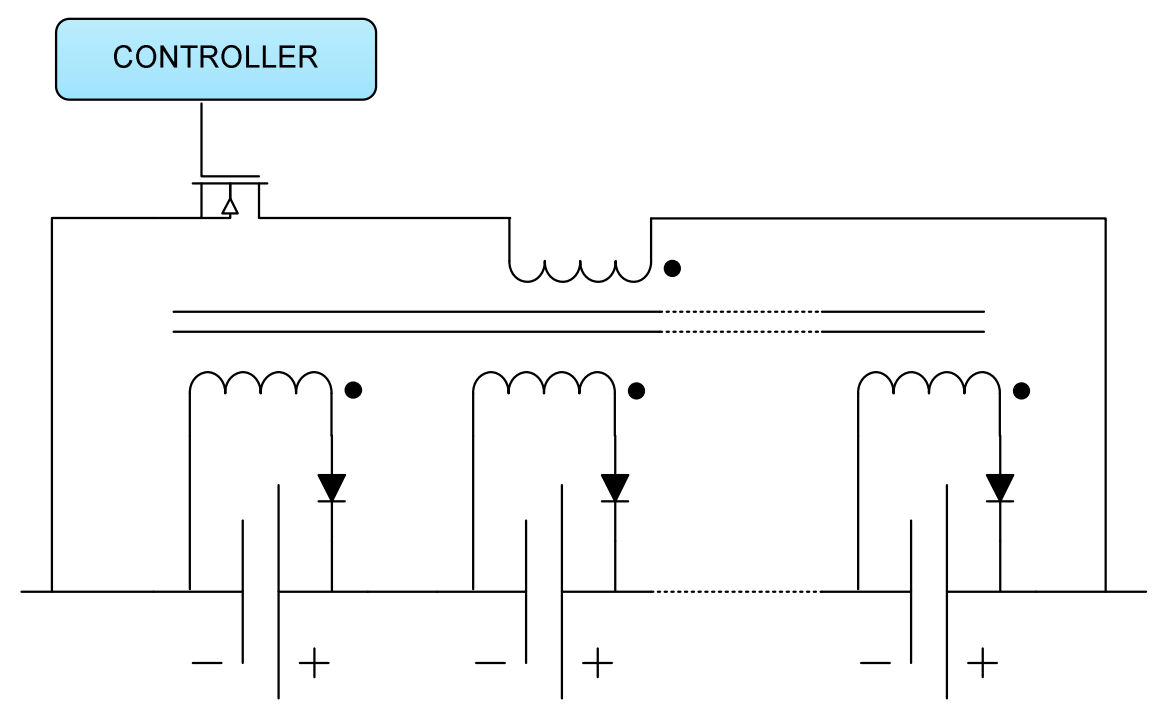

(b)

Figure 9. (a) Single inductor charge balancer, (b) shared transformer charge balancer. 
Using multiple transformers with each cell achieves similar results by coupling the cells with the primary windings instead of coupling via a single magnetic core (Moore \& Schneider, 2001; Hoque et al., 2017). However, the increased use of magnetics in this class of converters entails higher parts count and control complexities compared to capacitor-based converters. Moreover, scaling is difficult for transformer-based energy converters as additional taps cannot be easily added to accommodate more cells which necessitates a maximum number of cells as a pre-requisite for design.

Modular multi-level converters. Modular multi-level converters (MMC) have attracted wide interest from energy system designers due to their ability to operate over a wide range of switching frequency with low power losses (Zhao, Li, Jiang, Lu, \& Yuan, 2015). Furthermore, MMCs do not rely on capacitors, inductors, or transformers for energy sharing, signifying compact design. Thus, the modularity of MMCs can be leveraged for use in mobile power systems consisting of many energy cells. One of the proposed configurations for EV battery management using MMCs is shown in Figure 10 (Zheng, Wang, $\mathrm{Xu}, \& \mathrm{Li}, 2014$ ). This configuration uses a half-bridge MMC across each battery cell in series to form a modular architecture. The output of each phase leg is connected to an $\mathrm{H}$-bridge MMC that performs $\mathrm{DC}$ to AC conversion. The converter switches are operated based on a precedence-based charge/discharge procedure at a high frequency. Since each energy cell is connected to an MMC half-bridge, the controller is configured with a Pulse Width Modulation (PWM) switching scheme to discharge the high SOC cells more than the low SOC cells and vice-versa for charging. 


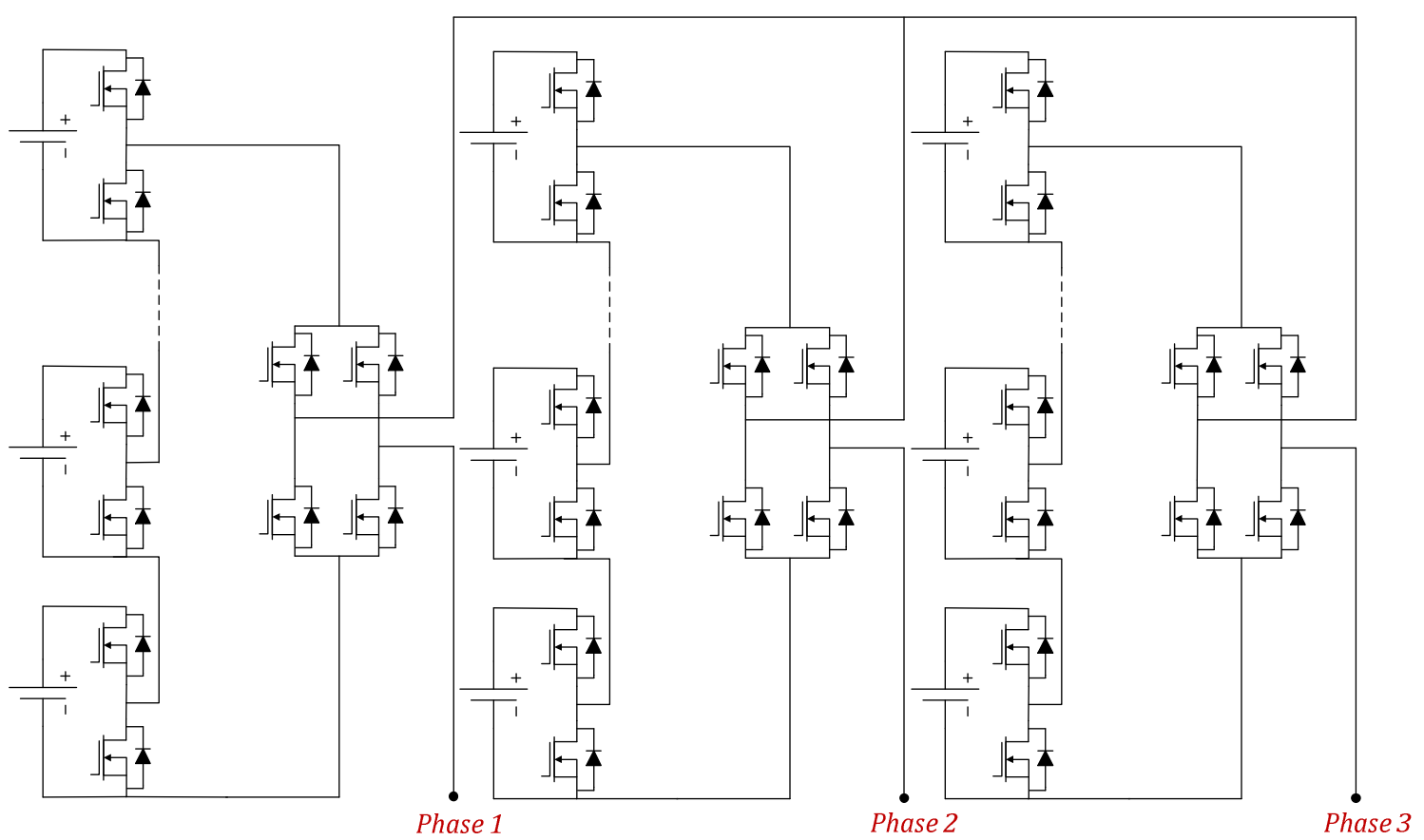

Figure 10. Three-phase modular multi-level converter configuration.

However, the above configuration performs well for a system consisting of either battery or UC cells. A Li-ion battery cell maintains its nominal OCV over a wide range of SOC $(20 \%-80 \%)$, while the OCV of the UC varies distinctly with its SOC. During high current discharge, the change in battery voltage is much slower than that of $\mathrm{UC}$, forming alternating signals with large total harmonic distortions. The resulting power losses limit system efficiency for such hybrid configurations. Therefore, employing the above configuration for efficient power processing will require a highly complex control strategy to accommodate the diverse cell dynamics of the battery and UC. 


\section{Summary}

The HESS configurations reviewed make a broad assumption regarding the uniform operation of individual cells in the battery or UC bank. While these configurations can achieve energy sharing on a pack level, the individual cell operation may limit system performance. Moreover, scaling of such configurations becomes an issue for high power applications without energy management on a cell level. In a practical scenario, the cells of each energy bank require additional charge balancing circuits.

The passive and active management schemes reviewed provide cell level energy balancing solutions. However, their implementation is limited to either battery or UC cells. Furthermore, the control techniques realized are mostly based on voltage differences between cells which is an impediment for Li-ion battery packs where cell OCV is not an accurate representation of SOC. 


\section{Novel Energy Management System}

\section{Overview}

In this chapter, the author proposes an MMC-based energy management system (EMS) architecture with cascaded battery and UC cells to enhance the power processing capabilities of EV battery packs. The intent was to leverage the energy density of battery cells for long-term power processing and utilize the power density of UCs for pulsated power processing. This could be achieved by reducing the stress on battery cells by throttling the high current drawn from them. Instead, the UCs could be used for supplying peak power during traction or accepting regeneration power during braking. Additionally, the conventional need for a system level drive inverter could be eliminated with the proposed HESS configuration. Many internal permanent magnet (IPM) motor applications rely on MTPA control for producing the desired torque from minimized current magnitudes (Bariša et al., 2015). In the proposed configuration, the MMCs could be controlled to extend the MTPA operation for increased system efficiency during high speeds. Moreover, the system control strategy was to be deployed such that a reduced number of switches would be used in every operational mode compared to conventional MMC configurations.

\section{Energy Management System Architecture}

The system framework of the proposed hybrid system for EVs is shown in Figure 11. The high voltage power pack was made up of low voltage sub-modules that store and supply energy to the EV motor. Within each sub-module, UCs cascaded with battery cells 
via DC-DC converters enabling both series and parallel configurations of the energy cells. The modular multi-level H-bridge inverter $(S 1-S 4)$ was used at the output of each sub-module, and the modular multi-level half-bridge converter $(S 5-S 6)$ was chosen for cascading the energy cells.

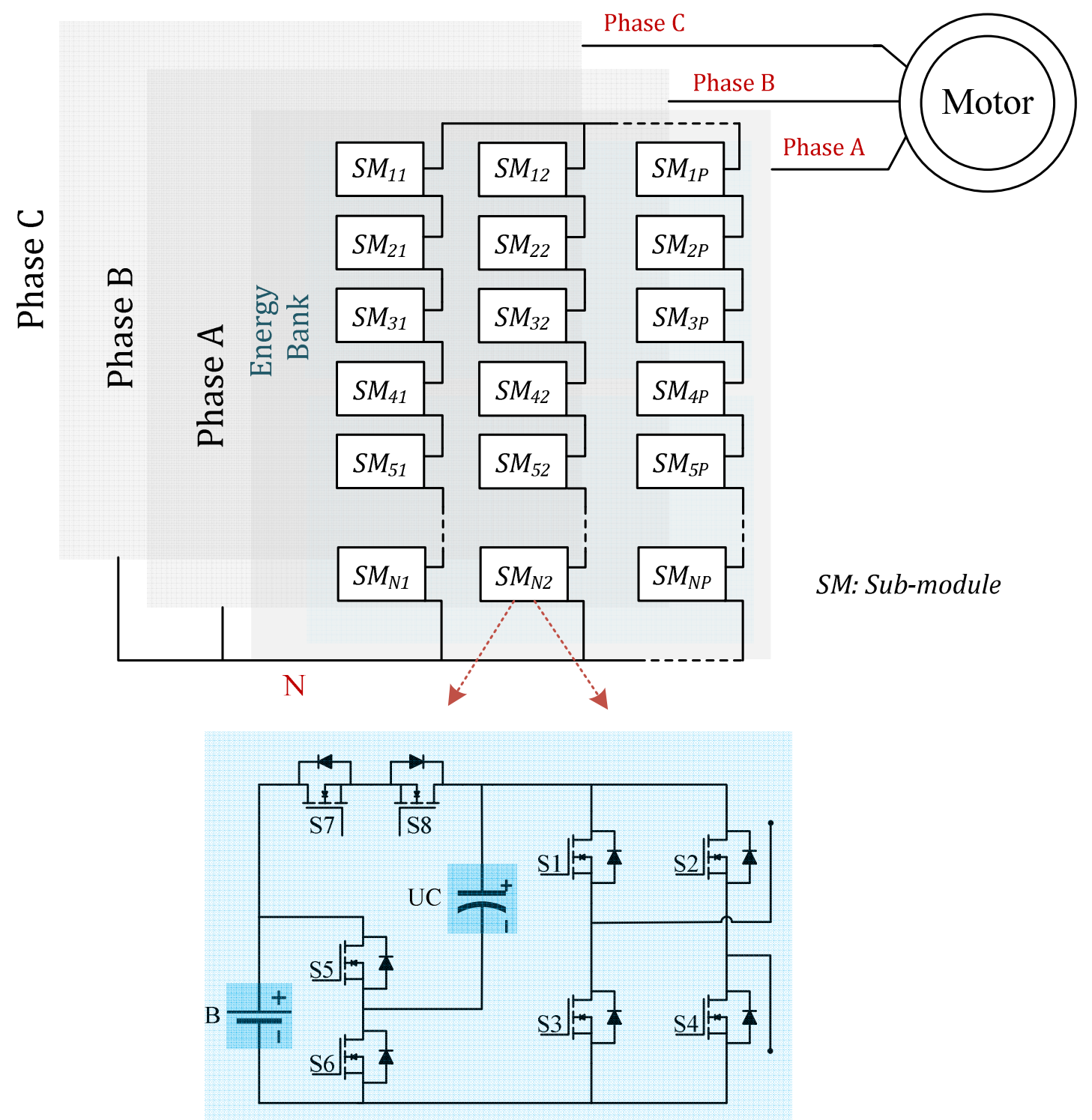

Figure 11. Novel hybrid energy-storage system for electric vehicles. 
Each sub-module was a hybrid converter structure that combined different MMCs. The proposed system was developed to extend the MTPA operation; hence, a series connection of the UC with the battery was allowed. High-side battery switching was achieved via two back-to-back switches $(S 7-S 8)$ that enabled bi-directional power flow. The dual-switch configuration also prevented unanticipated charge sharing between the energy cells due to leakage current or SOC imbalance. However, if the proposed system was to be developed for regular power modes, without accounting for MTPA control conditions, then the dual-switch could be replaced by a single switch in the converter structure.

The UC was always maintained at a voltage level lower than the nominal voltage of the battery cell. This was set as a prior constraint to account, in advance, for low voltage levels required during peak power fluctuations. Additionally, maintaining the UC voltage less than the battery cell voltage prevented mutual charge sharing since the anti-parallel diode of $S 6$ formed a parallel conduction path between the UC and battery cell. The UC was placed close to the H-bridge output to minimize conduction losses during peak power conditions. For $n$ sub-modules, there were $n$ battery cells, $n$ UCs, and $8 n$ switches with MTPA extension or $7 n$ switches without MTPA extension. The corresponding control strategy was developed in such a way that minimum number of converter switches were used for a given voltage level.

Moreover, the simple structure of sub-module converter allowed easy scaling of the HESS while establishing absolute control over the power contributions of each energy cell. The signals reaching the motor from the HESS were alternating waveforms that do 
not require any other form of inversion. This eliminated the need for a system level drive inverter present in conventional motor drives sized to invert high voltage DC signals. The three-phase connections in the main system framework carried three-phase alternating voltage and current waveforms to feed the motor. For higher current discharge, more parallel sub-module strings could be added for each phase. The HESS was sized on the basis of maximum, average, and minimum power demands of the EV motor. 


\section{Methodology}

\section{Converter Control Strategy}

The DC energy source of each sub-module was fixed with a multi-level H-bridge inverter at the sub-module output to perform DC-AC conversion. There were three alternatives for the DC source of a sub-module: Battery only, UC only, battery and UC. The corresponding conduction paths of the three modes are shown in Figure 12. During regular speeding conditions, when the power demand ranged from average to low, the current was drawn from the battery cells while bypassing the UCs (Figure 12a). During peak power fluctuations that occurred at high speeds, the low voltage UCs were connected to the output inverter while bypassing battery cells (Figure 12b). For speeds above the nominal motor speed, high voltage levels were to be maintained to keep the motor operating at MTPA. This was achieved by connecting both the battery cell and UC in series to serve as the DC source to the H-bridge inverter (Figure 12c). The modularity of these units coupled with easy switching control makes them suitable for high voltage drive applications that demand variable speed and, consequently, variable power.

Switching states. The switching states of the sub-module converters are detailed in Table 1 (also depicted in Figure 12). Analysis of the switch conduction losses revealed the efficiency merits of the proposed converter design. For a given voltage level, four switches were conducting in the battery-only mode, and only three switches were conducting in the UC-only and combined energy cell modes. Consequently, the minimum number of switches used per module reduced the conduction losses associated with high power transfer in the UC-only mode. 


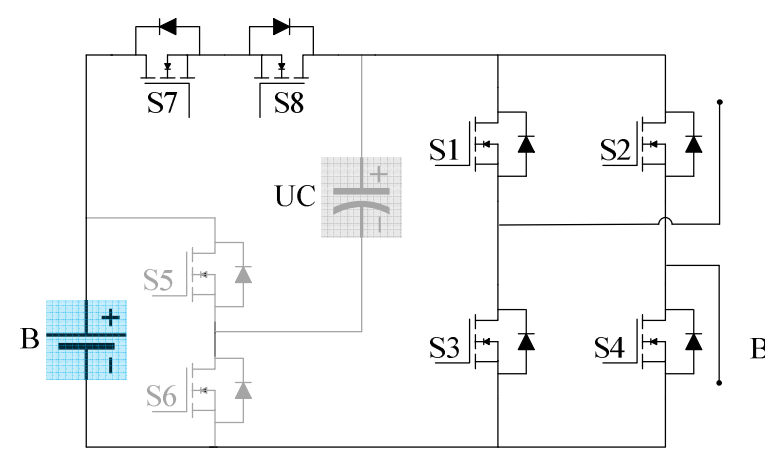

(a)

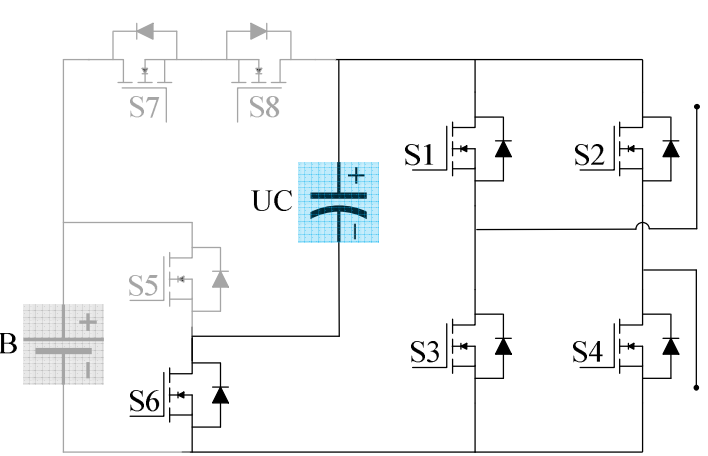

(b)

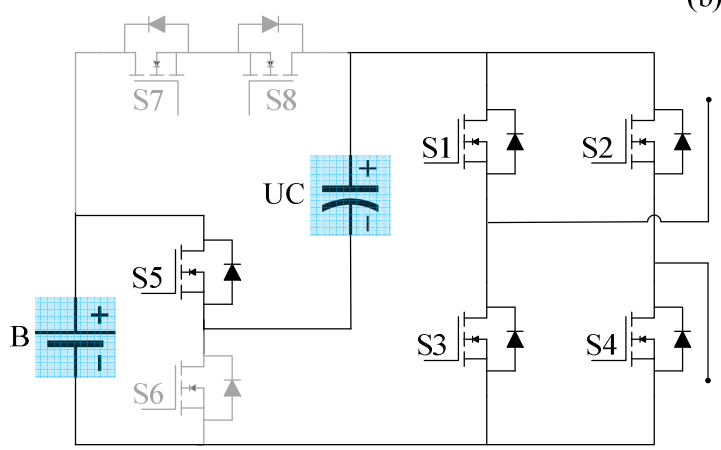

(c)

Figure 12. Conduction modes: (a) battery only, (b) ultracapacitor only, (c) battery + ultracapacitor.

Table 1: Sub-Module Converters Switching States

\begin{tabular}{|c|c|c|c|c|c|c|c|c|c|}
\hline Source : Mode & S1 & $S 2$ & S3 & S4 & S5 & S6 & S7 & S8 & Output \\
\hline \multirow{3}{*}{$\begin{array}{c}\text { Battery: } \\
\text { Low/average } \\
\text { power }\end{array}$} & 1 & 0 & 0 & 1 & 0 & 0 & 1 & 1 & $+\mathrm{Vdc}$ \\
\hline & 1 & 1 & 0 & 0 & 0 & 0 & 1 & 1 & 0 \\
\hline & 0 & 1 & 1 & 0 & 0 & 0 & 1 & 1 & $-\mathrm{Vdc}$ \\
\hline \multirow{3}{*}{$\begin{array}{l}\text { Ultracapacitor: } \\
\text { High power }\end{array}$} & 1 & 0 & 0 & 1 & 0 & 1 & 0 & 0 & $+\mathrm{Vdc}$ \\
\hline & 1 & 1 & 0 & 0 & 0 & 1 & 0 & 0 & 0 \\
\hline & 0 & 1 & 1 & 0 & 0 & 1 & 0 & 0 & $-\mathrm{Vdc}$ \\
\hline \multirow{3}{*}{$\begin{array}{l}\text { Battery + ultracapacitor: } \\
\text { Maximum torque per ampere }\end{array}$} & 1 & 0 & 0 & 1 & 1 & 0 & 0 & 0 & $+\mathrm{Vdc}$ \\
\hline & 1 & 1 & 0 & 0 & 1 & 0 & 0 & 0 & 0 \\
\hline & 0 & 1 & 1 & 0 & 1 & 0 & 0 & 0 & $-V d c$ \\
\hline
\end{tabular}


This design merit extended to the combined battery cell and UC mode as well. In a conventional hybrid system that has a single battery or UC for each H-bridge module, a minimum of four switches must conduct to establish a series path between two modules to obtain increased voltage levels. In the proposed converter design, only three switches were conducting when the battery and UC are in series (Figure 13). A significant reduction in sub-module conduction loss by approximately $25 \%$ was observed during MTPA operation, thereby improving system efficiency. The switching states remained the same during discharging, charging and regeneration cycles signifying consistent control procedure. Moreover, if any of the sub-modules had sources with extremely low levels of charge, the bypass modes were activated to remove those modules from the main conduction path. There were multiple switch combinations by which the 0 VDC bypass mode could be activated.

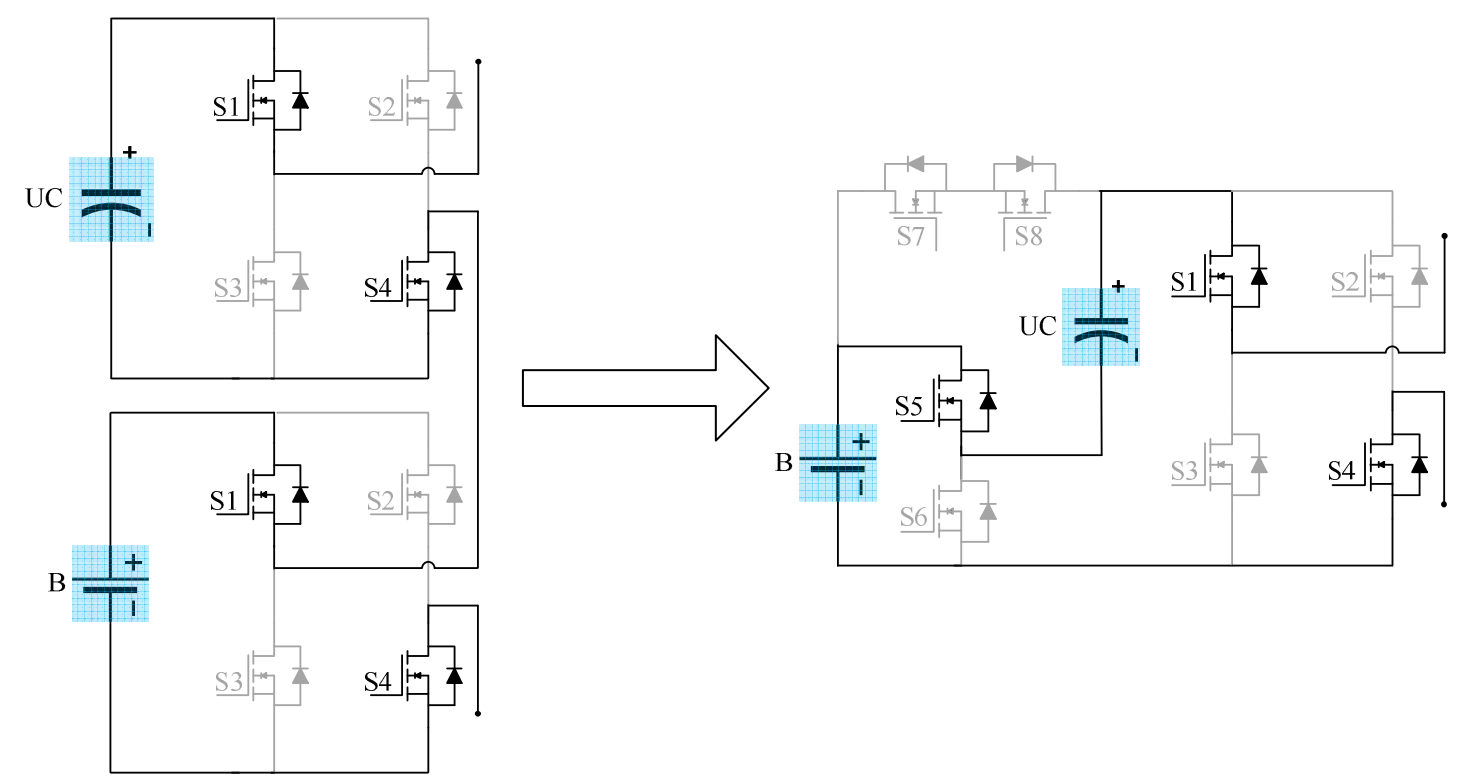

Figure 13. Conventional and novel converters for series-connected energy cells. 
Pulse width modulation scheme. Once the sub-module DC source was selected based on the mode of operation, the H-bridge inverters were switched using a PWM scheme. A multi-carrier technique called phase disposition PWM (PDPWM) was chosen for switching the H-bridge inverters (Figure 14). This method has been widely used for performing balancing and control of cascaded H-bridge inverter topologies (Raj, Jagadanand, \& George, 2016). High frequency carrier signals were stacked above and below the zero reference with $0^{\circ}$ phase shift. To obtain $p$ levels in the output waveform, $p-1$ carrier signals must be used. The carrier signals were assigned to different sub-modules based on their cell SOC levels. Reference signals with appropriate parameters (amplitude, frequency and phase) for the three-phase waveforms were defined and passed though the stacked carrier signals. The reference voltage waveform can be generalized for the three phases.

$$
V_{\text {ref }}=A \times m \times \sin (\omega t-\varphi)
$$

- $A$ is amplitude of the reference waveform that is set as the maximum of all the carrier signals.

- $m$ is the modulation index that allows selective switching of sub-modules by proportioning the amplitude of the reference wave.

- $\omega$ is the frequency of the reference wave which is set based on the required frequency of the output signal.

- $\varphi$ is phase shift in radians $(0,2 \pi / 3,4 \pi / 3)$ to produce three-phase reference signals. 
Stair-shaped sinusoidal waveforms were obtained from series connected versions of these sub-modules for each of the three phases. The waveform of a nine-level (eight non-zero levels and one zero level) voltage signal is demonstrated in Figure 14.

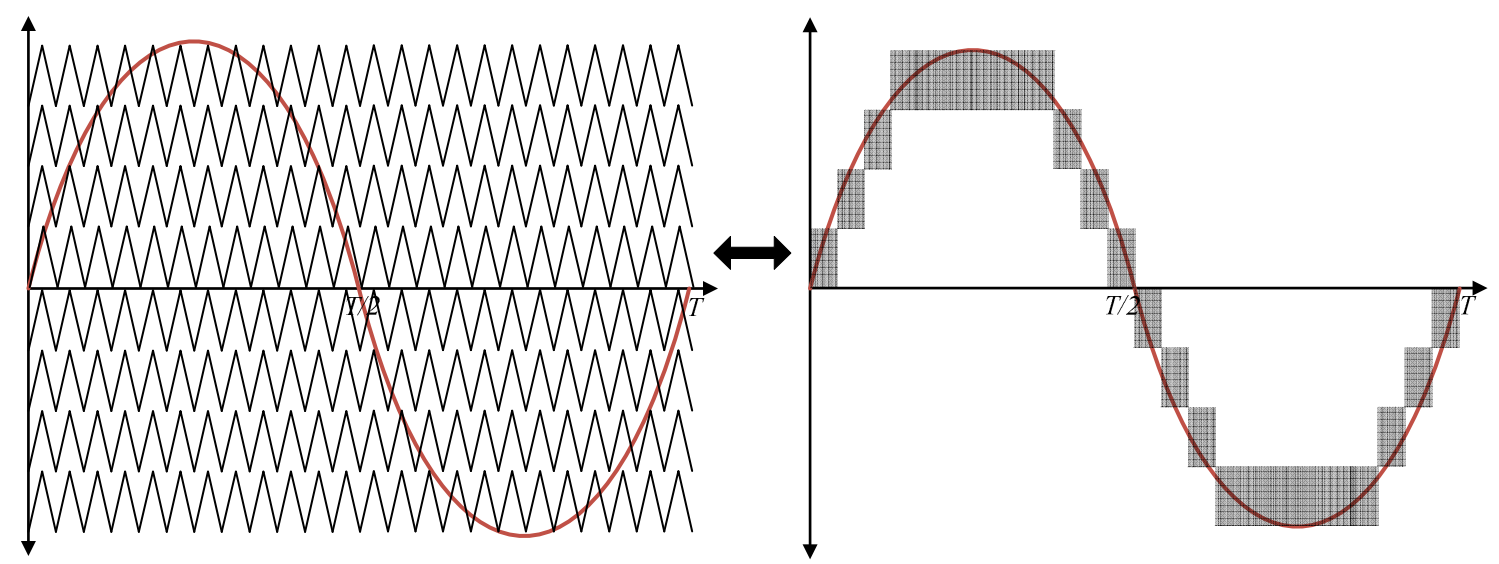

Figure 14. Pulse width modulation signals with output waveform.

State-of-charge estimation and balancing. The proposed HESS incorporates SOC estimation and charge balancing as functions of the EMS. The SOC of a battery cell and UC cell are represented by Eqn. (2) and (3), respectively.

$$
\begin{gathered}
S O C_{B}(t)=S O C_{B}(t-1)-\frac{I_{B}(t) \cdot T}{Q_{B_{N o m}}} \\
S O C_{U C}(t)=\frac{V_{U C_{-} O C}(t)}{V_{U C_{-} N o m}}
\end{gathered}
$$

The cell SOC was estimated for discrete time steps of $t=k T$ where $k$ is the discrete step and $T$ is sampling time. $I_{B}$ and $Q_{B_{-} N o m}$ are the battery current and nominal capacity, respectively. $V_{U C_{-} O C}$ and $V_{U C_{-} N o m}$ are the ultracapacitor OCV and nominal voltage, respectively. 
The order of precedence of charging and discharging of the energy cells was set based on online estimation of SOC. For discharge, the sub-modules were ordered from highest to lowest based on SOC. The corresponding PWM signals were updated every half cycle of the modulation wave when there was no current flow in the circuit. This was done to reduce harmonic distortions during converter switching. Consequently, the cells with high SOC were discharged more than the cells with low SOC. The order of precedence was reversed during battery charging and regeneration, i.e., the cells with low SOC would have higher precedence and would be charged more than the cells with high SOC. The algorithm is generalized in Figure 15.

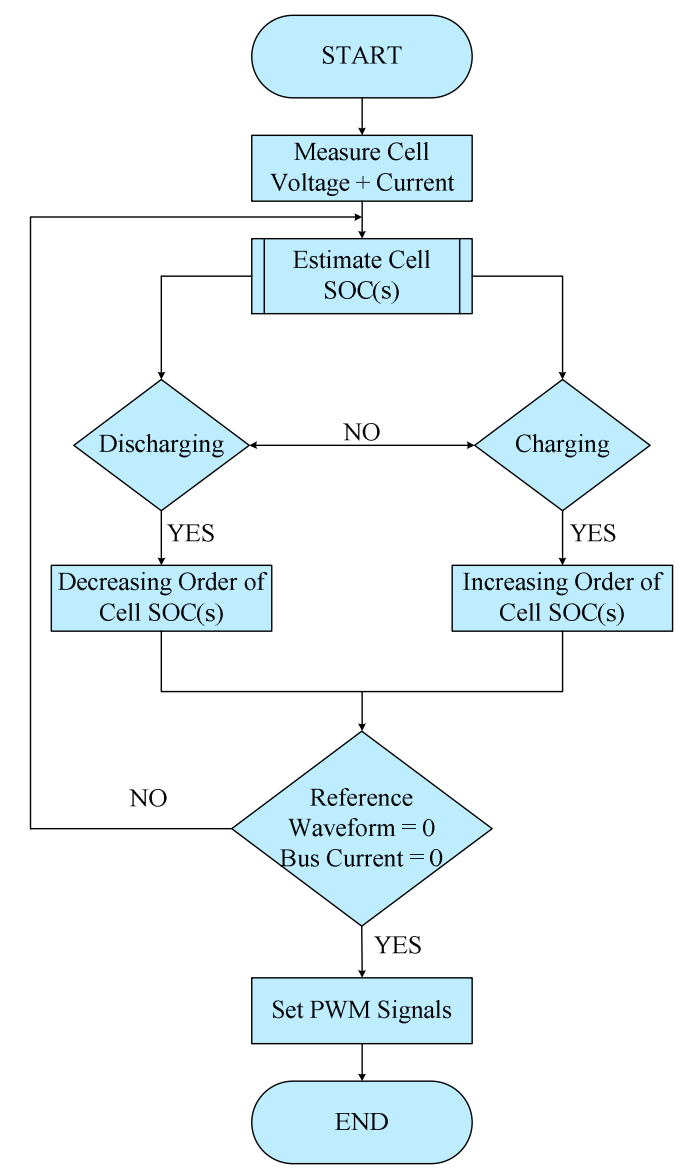

Figure 15. Cell state-of-charge estimation and balancing algorithm. 


\section{Energy Management System Hardware}

Hardware features. Printed circuit boards (PCBs) were designed to house the circuit components that implemented the proposed EMS. Design modularity was emphasized such that a master controller could be configured to drive multiple sub-module PCBs. Component selection was made to withstand high current conditions during system operation. Onboard voltage regulation allowed the circuit components to be supplied with appropriate input voltages. The main board schematic of a sub-module is shown in Figure 16. The off-page connections culminated as measurement and protection circuits connected to the digital controller. A single sub-module PCB arbitrated between a battery and UC pair via terminal ports. The sub-module output terminals were connected to neighboring sub-modules in a series string. The converters present on each sub-module allowed the energy cells to interface with the load. Converter switches $(S 1-S 8)$ were N-channel MOSFETs sized for high current charge and discharge. Bi-directional power switches $(S 7-S 8)$ were designed in the common source configuration to allow high-side battery switching. The gate drivers were housed on mountable PCBs to drive all the converter switches present on the sub-module board. One gate driver IC incorporated two isolated gate drivers with bootstrapping, as shown in Figure 17. Separate gate driver boards facilitated testing and verification of the prototype so that a board can be switched out in case of IC(s) failure. 


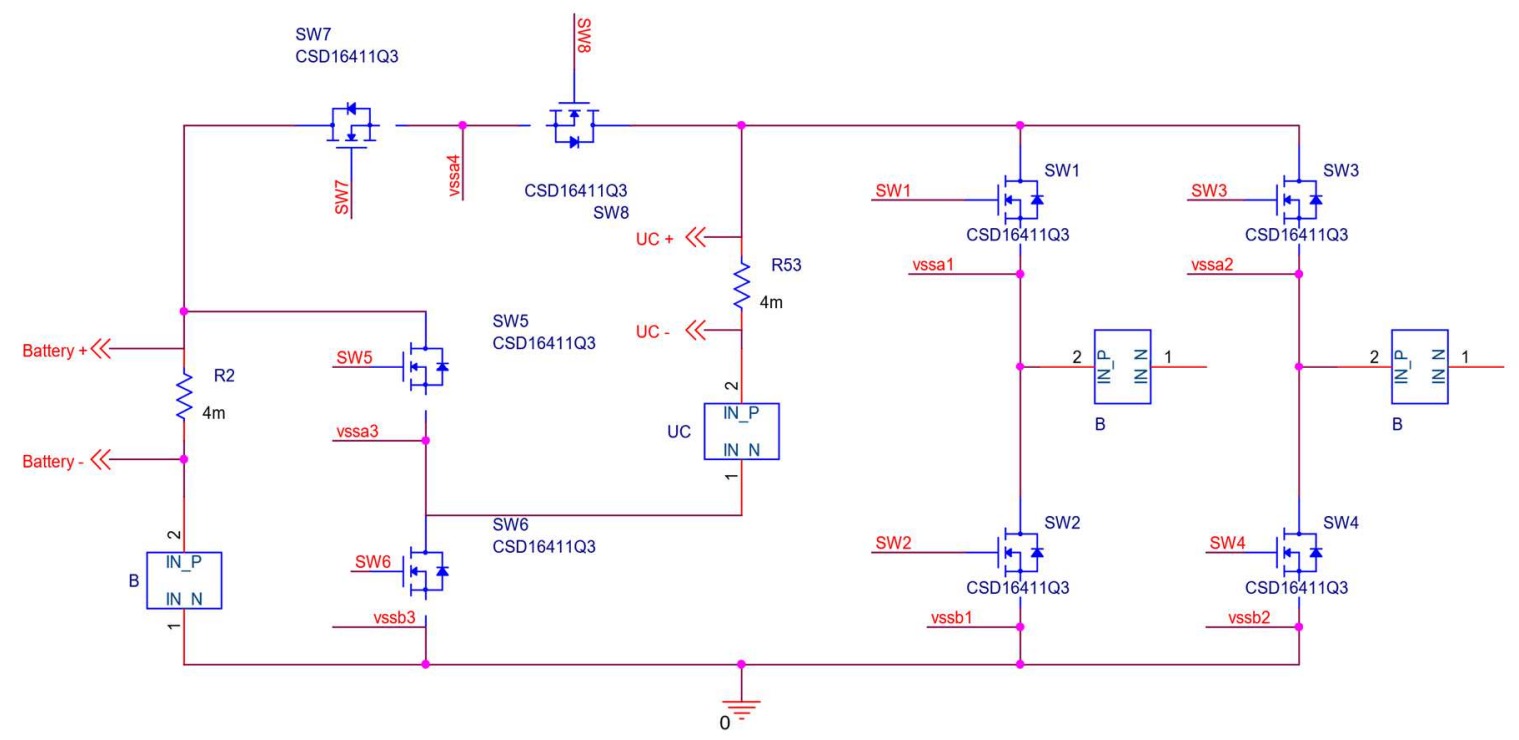

Figure 16. Sub-module board schematic.

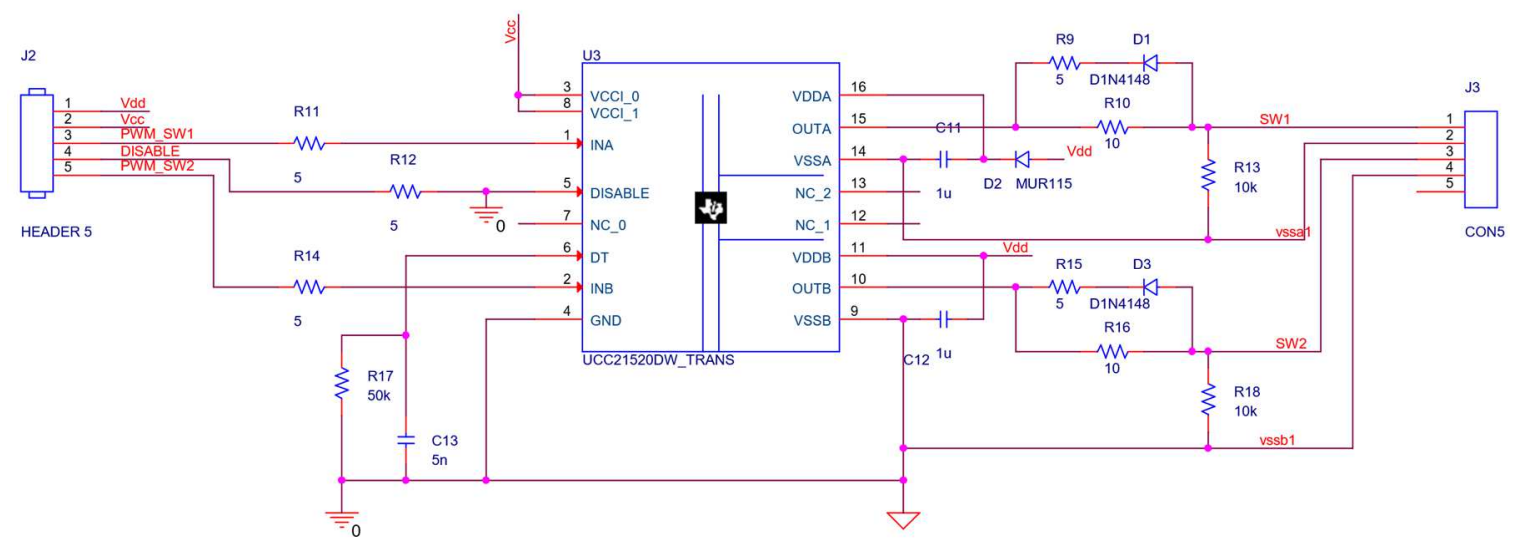

Figure 17. Gate driver circuit schematic.

Measurement. Each sub-module PCB consisted of voltage and current measurement circuits for every cell. Operational amplifier (Op-amp)-based circuits were adopted to sense and relay signals to the master controller. Voltage and current were measured using precision amplifier ICs with built-in isolation barriers to separate the output from the input circuitry. The isolation barriers enabled the ICs to resist magnetic interferences 
from neighboring circuitry and improve signal integrity. The voltage measurement circuit hosted an input divider that scaled the voltage values to the controller ADC specifications (Figure 18). Current measurement circuits were connected across sense resistors, as shown in Figure 19. Op-amp outputs were fed to the master controller that used the measured data to deploy the appropriate control strategy.

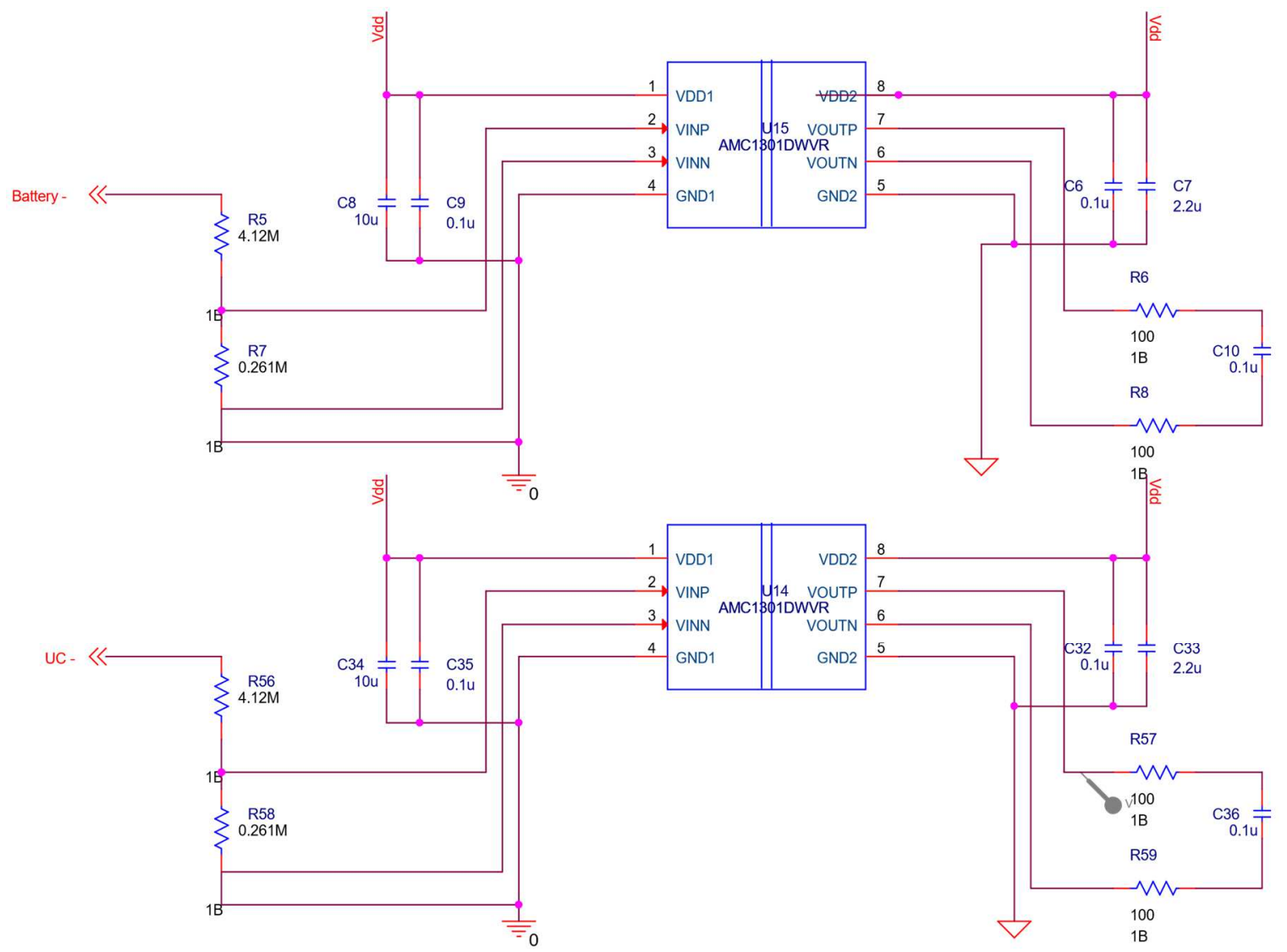

Figure 18. Voltage sensor circuit schematic. 


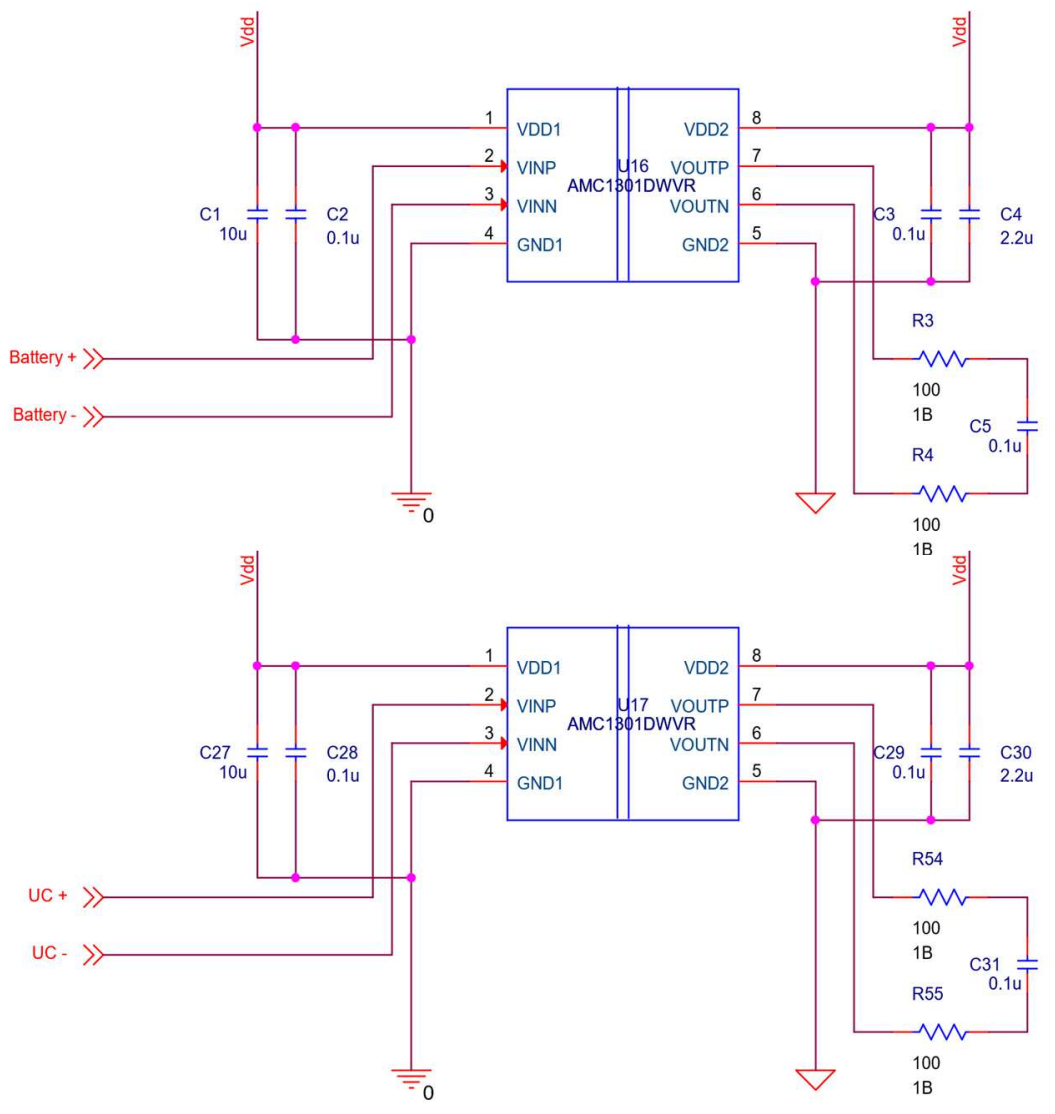

Figure 19. Current sensor circuit schematic.

Protection. The sub-module PCBs were designed with onboard protection for the energy cells which included overvoltage, undervoltage, and overcurrent protection. These protection circuits communicated with the master controller to ensure that the cells were not damaged under extreme loading conditions. Over-voltage protection was provided to both battery and UC cells to prevent them from exceeding their voltage limits. The comparator references were set to the upper bound values of $4.3 \mathrm{~V}$ and $3 \mathrm{~V}$ for the Li-ion cell and the UC, respectively. Under-voltage protection prevented the cells from being deeply discharged. The controller reference for cell empty voltage could be changed manually or estimated as per cell type. For Li-ion cells, voltage at empty tends to change 
with the load profile. In such cases, advanced cell empty-voltage estimation may be employed to make battery cell voltage approximations. Over-current protection for cells was achieved by programming the controller to cause incoming currents to bypass sub-modules with fully charged cells. Alternatively, hardware protection ICs could be included to prevent the energy cells from being subject to the aforementioned conditions.

Digital control. The master controller device chosen for executing energy management functions at a high frequency was the OPAL-RT OP4200. The controller was interconnected with the sub-module PCBs and the motor drive. The control methodology discussed in the previous section was programmed into the controller logic for a specific number of sub-modules. Current integration was used for battery and UC cell SOC estimation in the prototyped application. Given that the choice of cells could vary with the application scale, having a digital control device provided the advantage of modifying the algorithm engine to implement advanced parameter estimation techniques alongside cell SOC balancing. 


\section{Results}

The proposed HESS structure and operation were verified for systems with two and six sub-modules. Simulations were performed for different modes of operation based on the power requirements of the EV motor. The main controller inputs included cell states of charge, bus current, instantaneous power demand, available battery power, and available UC power. Discharging and charging (regeneration) cycles were identified based on these inputs. A threshold function to sense power fluctuation was configured that automatically switched the DC input of each sub-module during vehicle operation.

\section{Two Sub-Module System}

The two sub-module system triggered by the PDPWM scheme produced a five-level output waveform that drew current from different combinations of battery cells and UCs depending on the power mode.

Battery only (low/average power). During low and average power demand periods, current was drawn from the battery cells while the UCs were bypassed. The battery cells were initialized with $100 \%$ SOC, and the switches along their discharge path were activated. This resulted in a five-level alternating waveform with each cell contributing about $4 \mathrm{~V}$, as shown in Figure 20.

Ultracapacitor only (high power). During high power fluctuations, the battery cells were inactive and only the UC cells were discharged. The UC cells started the cycle with $100 \%$ SOC, and the switches along their discharge path were activated. This resulted in a five-level alternating waveform with each cell contributing a voltage level of $3 \mathrm{~V}$, as shown in Figure 21. 


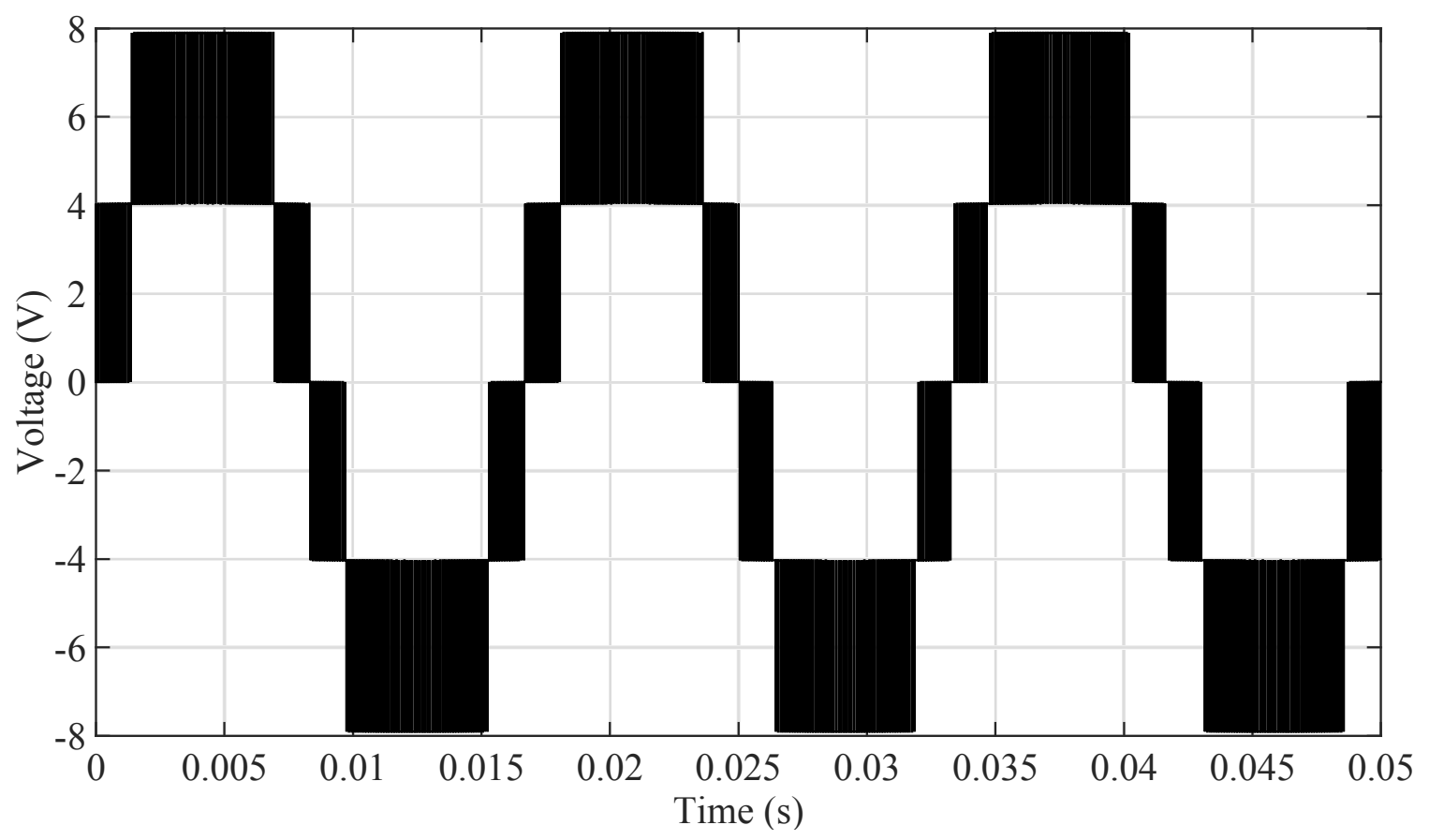

Figure 20. Five-level voltage waveform (battery only).

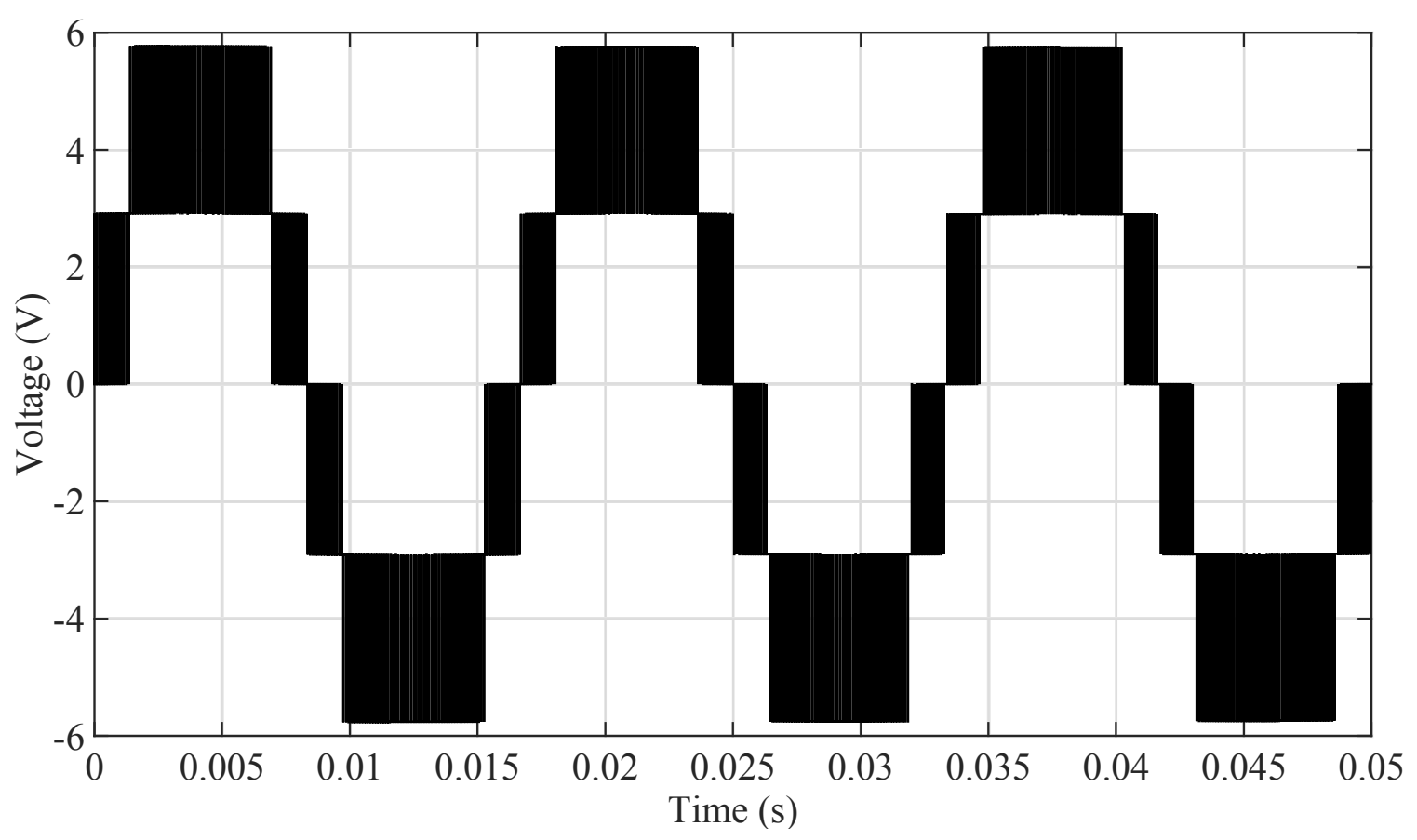

Figure 21. Five-level voltage waveform (ultracapacitor only). 
Battery and ultracapacitor (MTPA extension). High voltage levels are required to maintain efficient motor operation under MTPA conditions. These were supplied by series-connected battery and UC within each sub-module with all of the cells initialized at $100 \%$ SOC. The resulting five-level alternating waveform consisted of battery and UC cells contributing about $4 \mathrm{~V}$ and $3 \mathrm{~V}$, respectively, as shown in Figure 22.

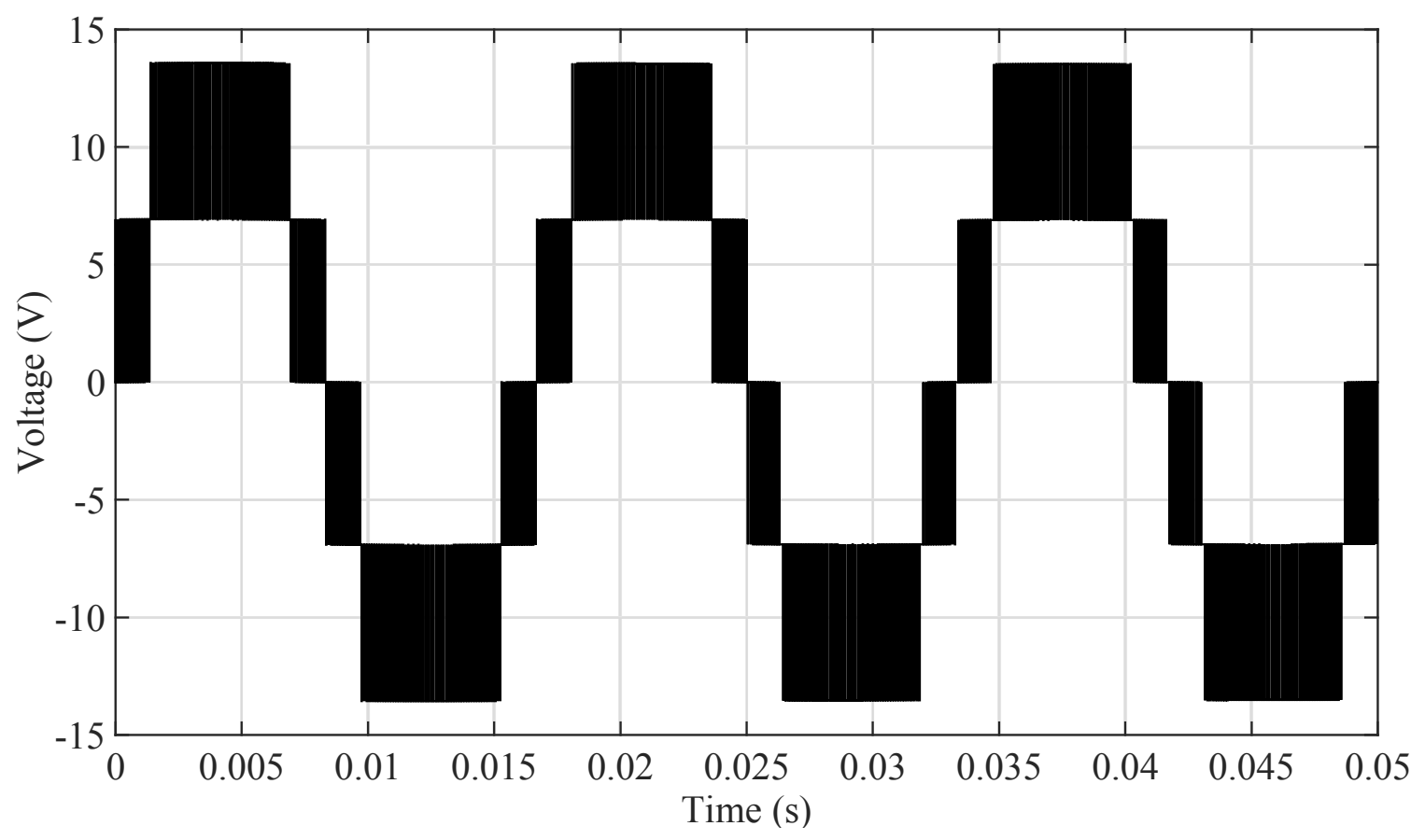

Figure 22. Five-level voltage waveform (battery + ultracapacitor).

\section{Three-Phase System}

In order to verify three-phase operation, the system was scaled up to include six sub-modules. The output converter switches of the sub-modules were triggered with the PDPWM scheme after having the reference signal adjusted to accommodate six sub-modules. The corresponding 13-level phase shifted waveforms could be used to power a three-phase EV motor (Figure 23). 


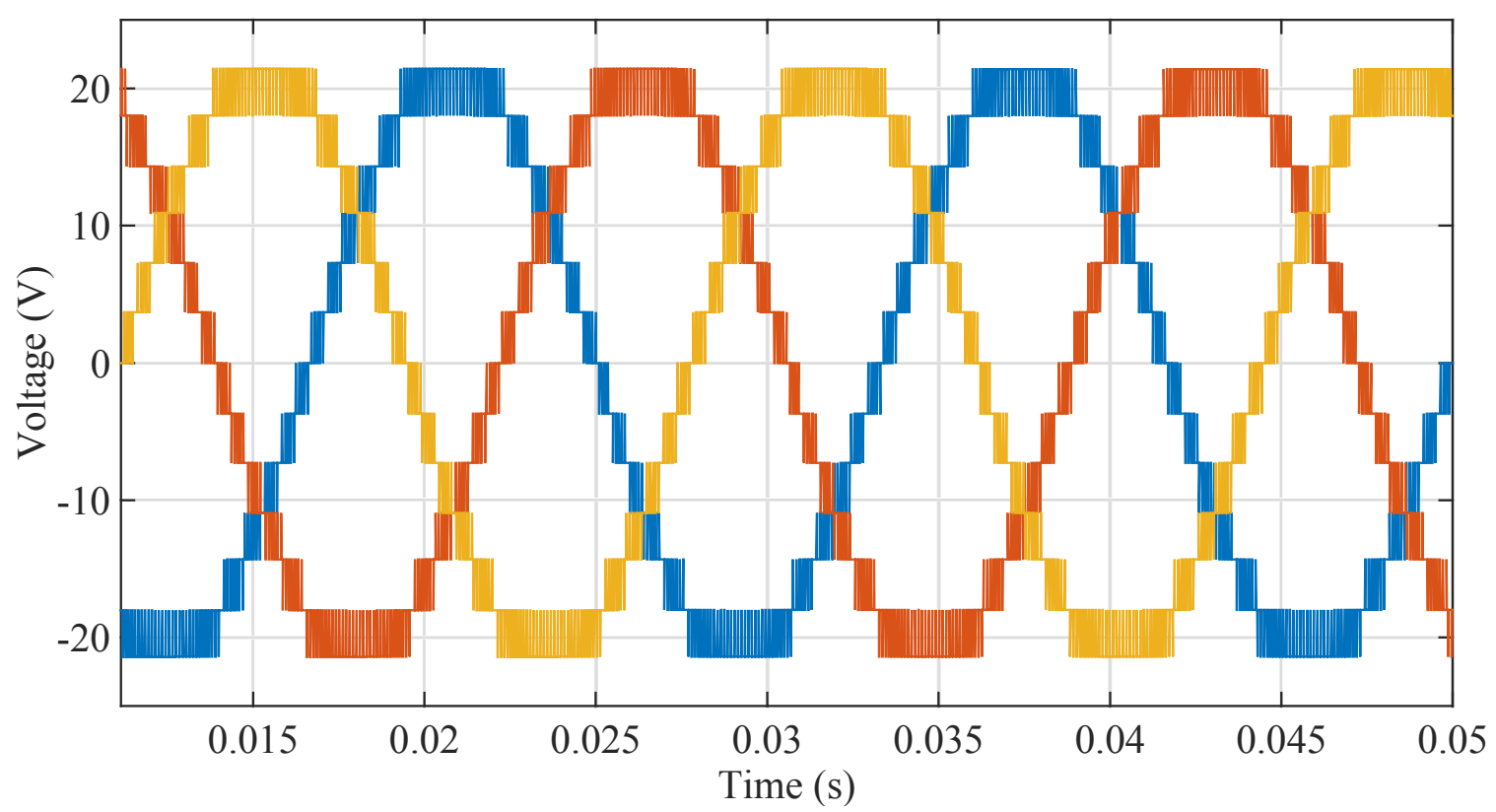

Figure 23. Three-phase voltage waveform.

\section{Energy Balancing of Six Sub-Modules}

The cell balancing action of the control scheme for six sub-modules is depicted in Figure 24. The system was tested with UCs initialized at different SOCs and a diverse current profile that consisted of high discharge and charge (regeneration) currents. Clearly, the cell with the highest initial SOC discharged more than the cell with the lowest SOC. A gradual decline in the discharge rate of cells from high to low SOC was observed. During regeneration, the low SOC cell charged faster, and the cell SOCs converged in the advancing cycles of discharge. A similar behavior was exhibited by the battery cells during discharging and charging cycles, although the cell dynamics were slower and required long periods of simulation. 


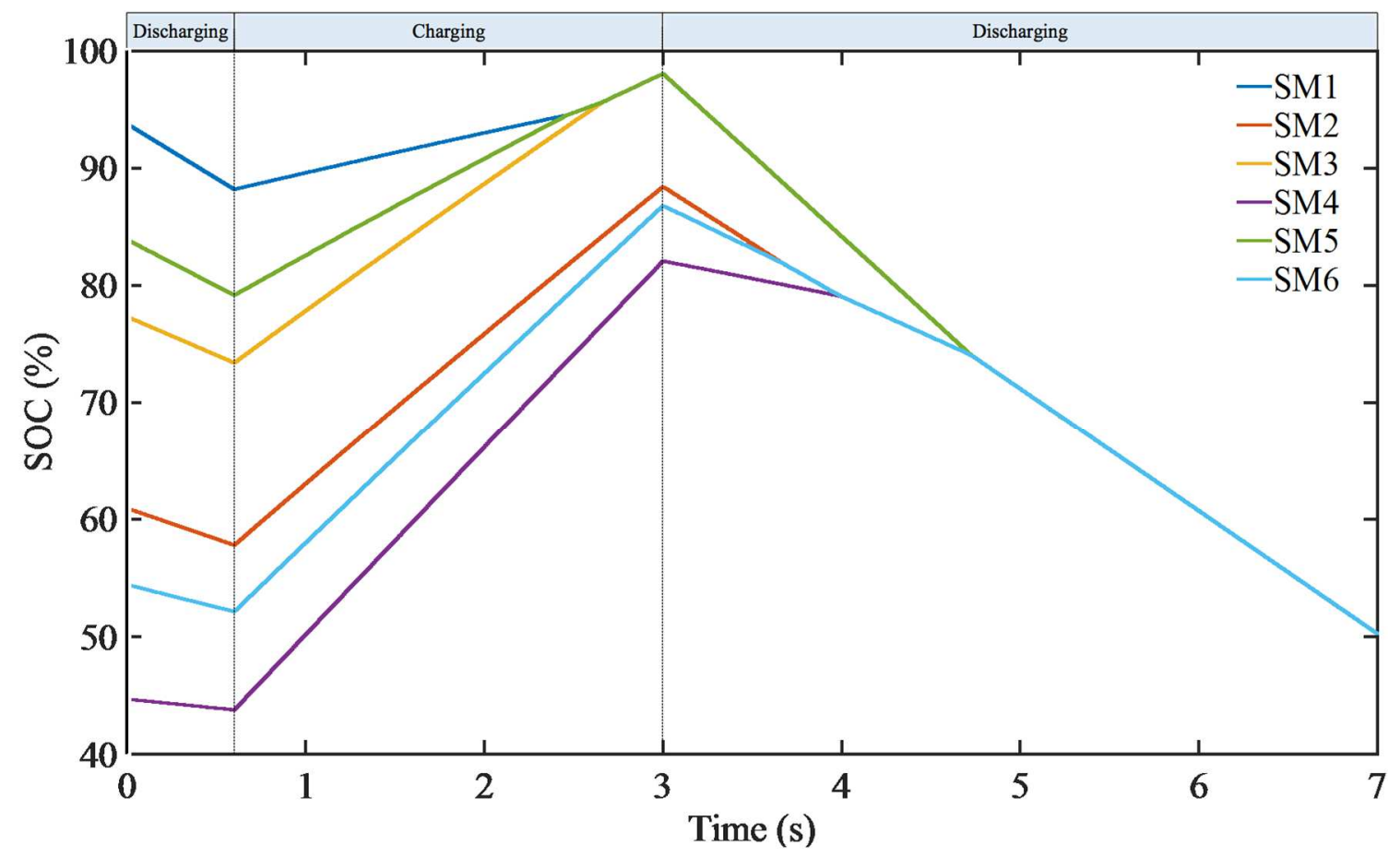

Figure 24. State-of-charge balancing of six sub-modules. 


\section{Conclusion and Future Work}

The proposed HESS adopted an MMC-based converter structure to manage the energy between battery and UC cells. The system has the ability to switch between high power, high energy and MTPA extension modes seamlessly. Additionally, the novel configuration eliminated the need for a system level drive inverter as the AC power signals were generated from the MMC modules. The control structure flexibility allowed easy implementation of energy management functions, some of which were presented in this study. The results indicate that the system can cater to various power demands while ensuring that the energy cells are efficiently utilized. The simplicity of the novel converter structure can aid in the development of high voltage energy packs without compromising power density.

Future work on this project is to improve the present scheme by introducing new performance metrics. The scope of improvements ranges from new design methods of the converter circuits, new digital control techniques, or incorporating other high-end motor drives. In many ways, research and development in EV energy management will create opportunities to improve the safety and reliability of systems powered by clean energy. This paves the way for mainstream adoption, thereby giving rise to a new era of sustainable transportation solutions that will play a significant role in alleviating the modern-day energy crisis. 


\section{References}

Agrawal, R. C., \& Pandey, G. P. (2008). Solid polymer electrolytes: materials designing and all-solid-state battery applications: an overview. Journal of Physics D: Applied Physics, 41(22), 223001.

All-Electric Vehicles. (2018). Retrieved from U.S. Department of Energy: https://www.fueleconomy.gov/feg/evtech.shtml

Andrea, D. (2010). Battery management systems for large lithium ion battery packs (1st ed.). Artech House.

Bariša, T., Sumina, D., \& Kutija, M. (2015). Comparison of maximum torque per ampere and loss minimization control for the interior permanent magnet synchronous generator. International Conference on Electrical Drives and Power Electronics, pp. 497-502. IEEE. doi:10.1109/EDPE.2015.7325344

BU-301a: Types of Battery Cells. (2017, July 31). Retrieved from Battery University: https://batteryuniversity.com/index.php/learn/article/types_of_battery_cells

BU-409: Charging Lithium-ion. (2018, April 24). Retrieved from Battery University: https://batteryuniversity.com/learn/article/charging_lithium_ion_batteries

Cao, J., \& Emadi, A. (2012). A new battery/ultracapacitor hybrid energy storage system for electric, hybrid, and plug-in hybrid electric vehicles. IEEE Transactions on Power Electronics, 27, pp. 122-132. IEEE. doi:10.1109/TPEL.2011.2151206

Etacheri, V., Marom, R., Elazari, R., Salitra, G., \& Aurbach, D. (2011). Challenges in the development of advanced Li-ion batteries: a review. Energy \& Environmental Science, 4(9), 3243-3262.

doi:10.1039/c1ee01598b

Gao, L., Dougal, R. A., \& Liu, S. (2005). Power enhancement of an actively controlled battery/ultracapacitor hybrid. IEEE Transactions on Power Electronics, 20, pp. 236-243. IEEE. doi:10.1109/TPEL.2004.839784

Gautam, D. S., Musavi, F., Edington, M., Eberle, W., \& Dunford, W. G. (2012). An automotive onboard 3.3-kW battery charger for PHEV application. IEEE Transactions on Vehicular Technology. 61(8), pp. 3466-3474. IEEE. doi:10.1109/TVT.2012.2210259 
Hoque, M. M., Hannan, M. A., Mohamed, A., \& Ayob, A. (2017). Battery charge equalization controller in electric vehicle applications: A review. Renewable and Sustainable Energy Reviews, 75, 1363-1385.

Kassens, E. (2009). Sustainable transportation: an international perspective. MIT Journal of Planning, 9, pp. 6-9.

Li, S., Mi, C. C., \& Zhang, M. (2013). A high-efficiency active battery-balancing circuit using multiwinding transformer. IEEE Transactions on Industry Applications, 49(1), pp. 198-207. IEEE. doi:10.1109/TIA.2012.2229455

Lu, L., Han, X., Hua, J., \& Ouyang, M. (2013). A review on the key issues for lithiumion battery management in electric vehicles. Journal of Power Sources, 226, $272-288$.

Lukic, S. M., Wirasingha, S. G., Rodriguez, F., Cao, J., \& Emadi, A. (2006). Power management of an ultracapacitor/battery hybrid energy storage system in an HEV. IEEE Vehicle Power and Propulsion Conference. IEEE. doi:10.1109/VPPC.2006.364357

Luo, X., Wang, J., Dooner, M., \& Jonathan, J. (2015). Overview of current development in electrical energy storage. Applied Energy, 137, 511-536.

Miller, M. A., Holmes, A. G., Conlon, B. M., \& Savagian, P. J. (2011). The GM "Voltec" 4ET50 Multi-Mode Electric Transaxle. SAE International Journal of Engines, 4(1), 1102-1114.

Moore, S. W., \& Schneider, P. J. (2001). A review of cell equalization methods for lithium ion and lithium polymer battery systems. SAE 2001 World Congress, Advanced Hybrid Vehicle Powertrains, pp. 1-5. SAE. doi:10.4271/2001.01.0959

Napoli, A. D., Crescimbini, F., Capponi, F., \& Solero, L. (2002). Control strategy for multiple input DC-DC power converters devoted to hybrid vehicle propulsion systems. IEEE International Symposium on Industrial Electronics, 3, pp. 1036-1041. IEEE. doi:10.1109/ISIE.2002.1025887

Ortúzar, M., Moreno, J., \& Dixon, J. (2007). Ultracapacitor-based auxiliary energy system for an electric vehicle: Implementation and evaluation. IEEE Transactions on Industrial Electronics, 54(4), pp. 2147-2156. IEEE. doi:10.1109/TIE.2007.894713 
Park, S., Kim, Y., \& Chang, N. (2013). Hybrid energy storage systems and battery management for electric vehicles. Proceedings of the 50th Annual Design Automation Conference, pp. 97-103, ACM. doi:10.1145/2463209.2488854

Park, S.-H., Kim, T.-S., Park, J.-S., Moon, G.-W., \& Yoon, M.-J. (2009). A new buckboost type battery equalizer. IEEE Applied Power Electronics Conference and Exposition, pp. 1246-1250. IEEE. doi:10.1109/APEC.2009.4802823

Raj, N., Jagadanand, G., \& George, S. (2016). A modified charge balancing scheme for cascaded H-bridge multi-level inverter. Journal of Power Electronics, 16(6), 2067-2075.

Williamson, S. S., Lukic, S. M., \& Emadi, A. (2006). Comprehensive drive train efficiency analysis of hybrid electric and fuel cell vehicles based on motorcontroller efficiency modeling. IEEE Transactions on Power Electronic, 21, pp. 730-740. IEEE. doi:10.1109/TPEL.2006.872388

Yuanmao, Y., Cheng, K. E., \& Yeung, Y. B. (2012). Zero-current switching switchedcapacitor zero-voltage-gap automatic equalization system for series battery string. IEEE Transactions on Power Electronics, 27(7), pp. 3234-3242. IEEE. doi:10.1109/TPEL.2011.2181868

Zhao, Z., Li, K., Jiang, Y., Lu, S., \& Yuan, L. (2015). Overview on reliability of modular multi-level cascade converters. Chinese Journal of Electrical Engineering. 1(1), pp. 37-49. CMP. doi:10.23919/CJEE.2015.7933136

Zheng, Z., Wang, K., Xu, L., \& Li, Y. (2014). A hybrid cascaded multi-level converter for battery energy management applied in electric vehicles. IEEE Transactions on Power Electronics. 29(7), pp. 3537-3546. IEEE. doi:10.1109/TPEL.2013.2279185 